Portland State University

PDXScholar

2-26-1996

\title{
Study Abroad and Self-perceptions of Cross-Cultural Adaptability
}

Heidi C. King

Portland State University

Follow this and additional works at: https://pdxscholar.library.pdx.edu/open_access_etds

Part of the Bilingual, Multilingual, and Multicultural Education Commons Let us know how access to this document benefits you.

\section{Recommended Citation}

King, Heidi C., "Study Abroad and Self-perceptions of Cross-Cultural Adaptability" (1996). Dissertations and Theses. Paper 5285.

https://doi.org/10.15760/etd.7158

This Thesis is brought to you for free and open access. It has been accepted for inclusion in Dissertations and Theses by an authorized administrator of PDXScholar. Please contact us if we can make this document more accessible: pdxscholar@pdx.edu. 


\section{THESIS APPROVAL}

The abstract and thesis of Heidi C. King for the Master of Arts in TESOL were presented February 26, 1996, and accepted by the thesis committee and the department.

COMMITTEE APPROVALS:
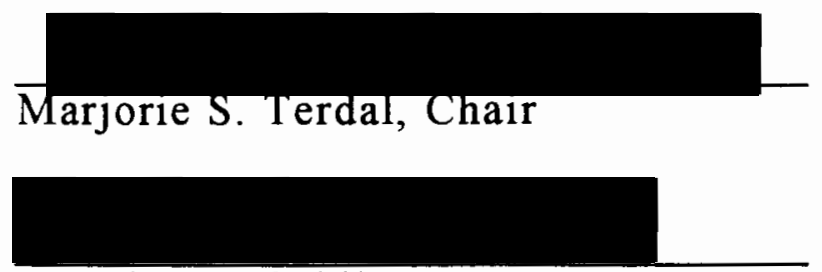

$$
\text { Beatrice T. Oshika }
$$

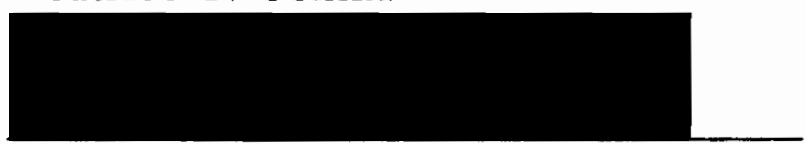

Susan B. Poulsen

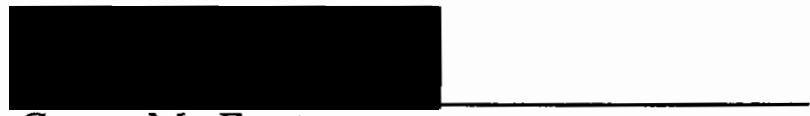

Grant M. Farr

Representative of the Office of

Graduate Studies

DEPARTMENT APPROVAL:

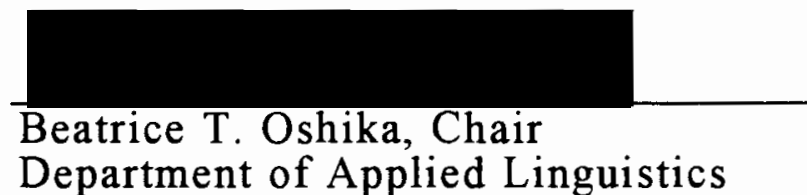

ACCEPTED FOR PORTLAND STATE UNIVERSITY BY THE LIBRARY
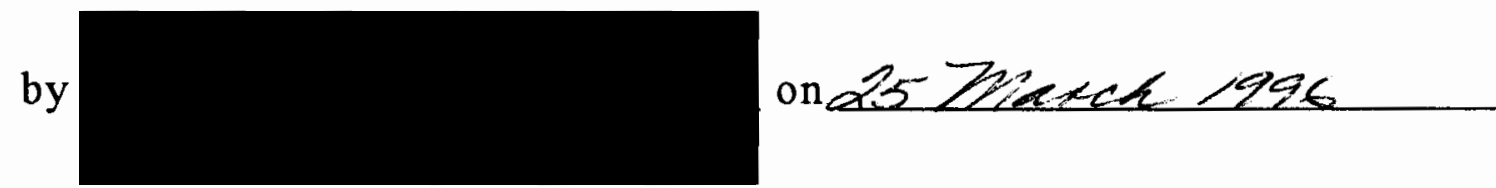


\begin{abstract}
An abstract of the thesis of Heidi C. King for the Master of Arts in TESOL presented February 26, 1996.
\end{abstract}

Title: Study Abroad and Self-Perceptions of Cross-Cultural Adaptability

With growing recognition of the duality of language and culture, the TESOL profession is placing increasing emphasis on the importance of understanding intercultural dynamics in the second language classroom. Currently, however, there is a lack of empirical information and measurement instruments to aid understanding within the field of cross-cultural communication. In response to this lack of instrumentation, Kelley and Meyers (1993) recently created the Cross-Cultural Adaptability Inventory (CCAI), a 50-item, self-perception inventory designed to measure cross-cultural adaptability through a total score and four contributing dimensions: Emotional Resilience, Flexibility/Openness, Perceptual Acuity and Personal Autonomy. The two primary purposes of this study were: (1) to add to a limited empirical base by studying the effect of four independent variables--host culture contact, cultural distance, second language proficiency, and length of previous experience abroad--on the dependent variable of cross-cultural adaptability; (2) to explore the possibility of using the CCAI for cross-cultural training in the TESOL profession. 
Two hundred and forty-five college/university students from two schools participated in the study. Subjects were selected based on location and length of previous cross-cultural experience abroad. Twenty-eight subjects with academic minors in TESOL were also specifically selected.

The statistical methodology of this study differed from that of Kelley and Meyers in its treatment of the CCAI Likert scale data as ordinal rather than interval data. After creating an index based on rank scores, one-way analysis of variance and Pearson's correlation coefficient were used for statistical analysis. Overall, the four primary variables of the study were shown to be significantly related to self-perceptions of cross-cultural adaptability. Of the four, cultural distance showed the weakest relationship. One scale, Personal Autonomy, stood out for consistently different results than those of the other three scales. Results were also discussed for TESOL vs, non-TESOL minors, age, gender, and satisfaction with sojourn abroad. 


\title{
STUDY ABROAD \\ AND SELF-PERCEPTIONS OF CROSS-CULTURAL ADAPTABILITY
}

by

HEIDI C. KING

A thesis submitted in partial fulfillment of the

requirements for the degree of

\author{
MASTER OF ARTS \\ in \\ TESOL
}

Portland State University

1996 


\section{ACKNOWLEDGMENTS}

There is always more than one way from here to there. I am grateful to the following people who not only directed and encouraged my routes in between but also cared how I got there:

Marge Terdal - thesis advisor and professor

Beatrice Oshika - thesis committee member, academic advisor, professor and department chair.

Grant Farr - thesis committee member and professor

Susan Poulsen - thesis committee member

Kim Brown, Jan DeCarrico, Kathy Harris - TESOL professors

Wes Brenner (PSU), Duane Kauffmann (Goshen College) - statistics consultants without whom chapters IV and V would not exist.

Research Participants

Eastern Mennonite University (Harrisonburg, VA)

Orval Gingerich - director of study abroad programs

The Alumni Office - selection of participants

Goshen College (Goshen, IN)

Wilbur Birky - director of study abroad programs

Janelle Martin, Stan Miller - selection of participants

Cindy Tatman, Ed Kiefer - printing and mailing

Pilot Study Participants - invaluable feedback

Subjects - all 245 of whom have forever changed my views on filling out surveys

Ultimately, for me, none of this would have mattered without my parents, family, friends and God, whom I believe created all heres and theres. 


\section{TABLE OF CONTENTS}

PAGE

ACKNOWLEDGMENTS $\ldots \ldots \ldots \ldots \ldots \ldots \ldots \ldots$ ii

LIST OF TABLES $\ldots \ldots \ldots \ldots \ldots \ldots \ldots \ldots \ldots \ldots \ldots \ldots \ldots \ldots \ldots$

\section{CHAPTER}

I INTRODUCTION $\ldots \ldots \ldots \ldots \ldots \ldots \ldots \ldots \ldots$

Background ...................... 1

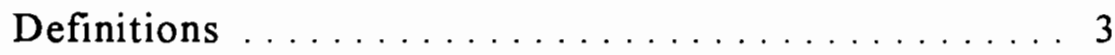

Research Questions ................. 4

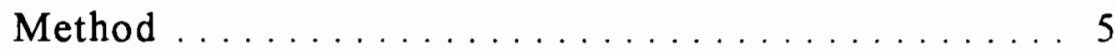

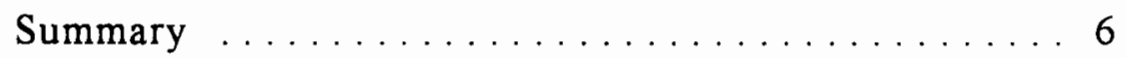

II REVIEW OF THE LITERATURE $\ldots \ldots \ldots \ldots \ldots$

Introduction $\ldots \ldots \ldots \ldots \ldots \ldots \ldots \ldots$

Terminology

Models of Intercultural Effectiveness . . . . . . . 10

Trait Model

Task/Situational Theory--Performance Based

Competence

Bennett's Model of Intercultural Competence

Rationale for Study Abroad ............... 14

Culture Shock

Passive vs Active Learning 
Four Variables of Cross-Cultural Adaptability

Host Culture Contact

Cultural Distance

Second Language Proficiency

Length of Previous Experience Abroad

The Present and Future of Study Abroad 28

Summary 28

III METHODOLOGY

Subjects

Participants

Participating Institutions

Instrument and Materials

The Cross-Cultural Adaptability Inventory (CCAI)

Demographic Questionnaire

Form Letter

Materials Included for High Return

Procedures

Data Analysis 44

IV RESULTS 48

Introduction 48

Research Questions

Host Culture Contact

Cultural Distance

Second Language Proficiency

Length of Previous Experience Abroad

Analyses for TESOL Minors 62

Age, Gender, and Satisfaction 
V SUMMARY AND CONCLUSIONS ............ 70

Overall Findings $\ldots \ldots \ldots \ldots \ldots \ldots \ldots \ldots \ldots$

Observations for Significant RPA's

RPA vs RFO

Research Questions .................. 76

Host Culture Contact

Cultural Distance

Second Language Proficiency

Length of Previous Experience Abroad

Field of Study

Age, Gender, \& Satisfaction Abroad

Limitations . . . . . . . . . . . . . . . . . . . 83

Objectivity

Intervening Variables

Generalizability

Data Analysis

The Value of This Study

The Cross-Cultural Adaptability Inventory (CCAI)

Empirical Results

Implications for ESL . . . . . . . . . . . . 91

Suggestions for Future Research . . . . . . . . 92

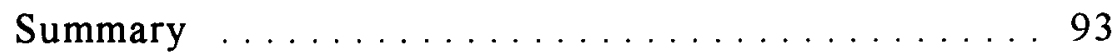

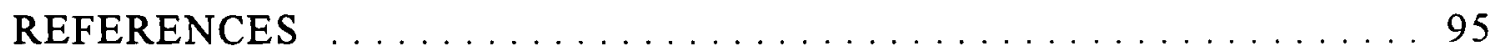

APPENDICES

A Form Letter: Eastern Mennonite University and

Goshen College

B Demographic Survey: Eastern Mennonite University and

Goshen College 
C Categories for Majors/Minors ................ 109

D Categories for Locations . . . . . . . . . . . . . 111 
CCAI Pearson and Spearman Product-Moment

Correlations Among Scale and Total Score Ranks ... 50

II Correlations of Percentage of Host Culture Interaction with CCAI Scale and Total Ranks Means, F Probabilities and $\mathrm{H}$ Probabilities for

CCAI Scale and Total Ranks for Sojourners

Living in Dorms/Hotels and Sojourners

Living with Host Families

IV Correlations of Perceived Cultural Distance with CCAI Scale and Total Ranks .................. 53

Means, F Probabilities and H Probabilities for CCAI Scale and Total Ranks for Adjustment During Experience Abroad

VI Means, F Probabilities and H Probabilities for CCAI Scale and Total Ranks for Adjustment After Experience Abroad

VII Means, F Probabilities and H Probabilities for CCAI Scale and Total Ranks for Change in Level of Difficulty from Adjustment During Sojourn to Adjustment After Sojourn

VIII Means, F Probabilities and H Probabilities for CCAI Scale and Total Ranks for Subjects' L2 Fluency

IX Means, F Probabilities and H Probabilities for CCAI Scale and Total Ranks for Parent/s' L2 Fluency 
$\mathrm{X}$

$\mathrm{XI}$

XII

XIII

XIV

XVI

XVIII

XIX

$\mathrm{XX}$

Means, F Probabilities and H Probabilities for CCAI Scale and Total Ranks for L2 Fluency for Parent/s \& Subjects 58

Means, F Probabilities and H Probabilities for CCAI Scale and Total Ranks for Skill in Host Culture L2

CCAI Pearson and Spearman Product-Moment Correlations with Percent Use of Host Culture L2 . . . . . . . . 60

CCAI Pearson and Spearman Product-Moment Correlations with Total Time Abroad

Means, F Probabilities and H Probabilities for CCAI Scale and Total Ranks for Total Previous Cross-Cultural Experience

Means, F Probabilities and H Probabilities for CCAI Scale and Total Ranks for Minor Area of Study

Means, F Probabilities and H Probabilities for CCAI Scale and Total Ranks for TESOL vs Non-TESOL Minors 64 Means, F Probabilities and H Probabilities for Time, Percent Interaction, and L2 Use During Experience Abroad for TESOL vs Non-TESOL minors 64 Means, F Probabilities and $\mathrm{H}$ Probabilities for Adjustment During and After Sojourn Abroad and Total Time of Experience Abroad for TESOL and Non-TESOL Minors . . . . . . . . . . . . . 64

CCAI Pearson and Spearman Product-Moment Correlations with Age

Means, F Probabilities and H Probabilities for CCAI Scale and Total Ranks for Age 
XXI Means, F Probabilities and H Probabilities for CCAI Scale and Total Ranks for Gender ............... 67

XXII Means, F Probabilities and H Probabilities for CCAI Scale and Total Ranks for Satisfaction with Experience Abroad ....................668 68

XXIII Means, F Probabilities and H Probabilities for Time, Percent of Interaction with Host Culture and Percent of Host Culture L2 Use By Satisfaction .................... 68 XXIV Summary of CCAI Difference of Means and Correlations for All Variables 


\section{CHAPTER I}

\section{INTRODUCTION}

\section{BACKGROUND}

The keystone of all successful teaching-learning situations is good communication, for the acquisition of knowledge is predicated upon an accurate exchange of information between the instructor and his students. This factor is particularly crucial in classes where teacher and students are of different background, and where the learning process may be inhibited by cross-cultural interferences. (Condon, 1984, p. 108)

For second language teachers whose job is defined by interaction with learners from a potentially wide variety of cultures, it seems only logical to view cross-cultural adaptability as desirable, if not necessary, for success in teaching second language learners. Current pedagogy in second language learning falls in line with this rationale, calling teachers to view language not as an entity in isolation but as carrying meaning in the context of interaction. From this perspective, language learning and teaching encompass not only linguistic knowledge but social and, therefore, cultural behavior as well. Simply put, this means that the language teacher cannot and should not provide instruction without reckoning with the cultural aspects of the second language classroom. Damen (1987) advocates that second language teachers become cultural mediators, or active links, between different cultures as an integral part of their teaching.

This emphasis on the duality of language and culture learning/teaching has only recently begun to take root within the field of professional language educators (Allen, 1993; Condon, 1984). Understanding and measurement of the construct of cross-cultural adaptability (as a part of the larger field of cross-cultural communication) is also relatively 
new. Thus, it seems that trainers of second language educators who are indeed interested in helping teachers to communicate effectively across different cultures, first face the challenge of establishing a clearer understanding of cross-cultural adaptability and variables related to the construct.

The primary purpose of this study was to address one avenue of this challenge by focusing on the study abroad experience as a commonly assumed way of enhancing crosscultural adaptability. To quote Matthews (1988):

International education of students can, of course, be accomplished without overseas programs, particularly in light of the availability of modern electronic transmissions of news, cultural events, sports and education programs, and many institutions would wisely consider such options. But the firsthand experience provided by international educational exchange or foreign study has the potential to develop true internationalists. (p. 376)

Numerous variables have been suggested as influencing factors of intercultural learning through study abroad; however, not much empirical evidence is available to support these claims (Koester, 1987; Martin, 1987). This lack of empirical evidence is most likely due to (1) the newness of the field of intercultural communication resulting in unclear conceptualization of related constructs such as cross-cultural adaptability and (2) a lack of available instrumentation to measure cross-cultural adaptability. Both of these factors have resulted in a disparity of 1) definitions and 2) measurement of cross-cultural adaptability.

A secondary purpose of this study was to gain familiarity with the Cross-Cultural Adaptability Inventory (hereafter referred to as the CCAI) in order to examine the appropriateness of its use in assessing and/or encouraging the cross-cultural adaptability of ESL teachers. For the ESL profession, an instrument such as the CCAI could be a valuable source of cross-cultural learning for teachers-in-training. 


\section{DEFINITIONS}

Because of the problems of definition and methodology in this study, it is both especially important and especially difficult to define terms with perfect clarity. The following is an attempt to come to terms with this by briefly giving what clarity is possible for the reader's future reference in this study. (See Chapter II for a more in-depth discussion on variation in terminology and methodology.)

Cross-cultural/intercultural - involving two or more cultures which differ from each other. These two words are used interchangeably both in the literature and in the present study. Cross-Cultural Communication/Intercultural communication - any form of communication, verbal or nonverbal, which occurs intentionally or unintentionally between two or more persons of differing cultures.

Cross-cultural adaptability - the degree to which one possesses the ability to interact with a person or persons of a culture different from one's own in such a way that meaning both given and received corresponds with intended meaning. Kelley and Meyers (1993), authors of the Cross-cultural Adaptability Inventory--the instrument used for this study--assign four dimensions to the construct of cross-cultural adaptability defined in short as follows: (Note: See Chapter III for further discussion of these dimensions.)

(1) Emotional Resilience - the ability to deal with stressful feelings in a constructive way and to "bounce back" from them. Also, the ability to cope with ambiguity and to enjoy new experiences.

(2) Flexibility/Openness - the ability to feel comfortable and enjoy interacting with a wide variety of people who think differently from oneself.

(3) Perceptual Acuity - attentiveness to verbal and nonverbal behaviors, to the context of communication, and to interpersonal relations. Being sensitive to the feelings of others and to one's impact on others. 
(4) Personal Autonomy - Having a strong sense of one's self and personal values with respect for self and others. Self directed and "at home" in any environment.

Sojourner - one who lives or travels in another culture for an unspecified amount of time with the intent of being temporary rather than permanent in that culture.

Cultural distance - the degree of differentness between two given cultures, most often in reference to 1) one's home culture and 2) the host culture of one's sojourn experience.

\section{$\underline{\text { ACRONYMS }}$}

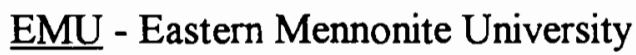

CCS - Cross-cultural Seminar, or study abroad, at Eastern Mennonite University

GC - Goshen College

SST - Study-Service Term, or study abroad, at Goshen College

CCAI - Cross-Cultural Adaptability Inventory

\section{RESEARCH QUESTIONS}

The Cross-cultural Adaptability Inventory (CCAI), a 50-item culture-general, selfawareness questionnaire, appears to be one of the few readily available cross-cultural adaptability assessment and training instruments of its kind. In an attempt to add to a currently limited empirical base (of both the cross-cultural field and the CCAI), this study used the CCAI as a means of examining the relationship of the dependent variable, crosscultural adaptability, with four independent study abroad variables cited in the literature as relevant to intercultural learning: host culture contact, cultural distance, second language proficiency, and length of previous experience abroad. Students with academic minors in 
TESOL were targeted as a subgroup of special interest in the study.

The following questions address the relationship of the four specific variables listed above with self-perceptions of cross-cultural adaptability:

1. Is there a significant relationship between host culture contact during previous experience abroad and self-perceptions of cross-cultural adaptability?

2. Is there a significant relationship between cultural distance of previous study abroad experience and self-perceptions of cross-cultural adaptability?

3. Is there a significant relationship between second language proficiency and selfperceptions of cross-cultural adaptability?

4. Is there a significant relationship between length of previous study abroad experience and self-perceptions of cross-cultural adaptability?

Chapter III itemizes specific questions used to identify/quantify these four variables.

\section{METHOD}

Data for this study were elicited through the mail using the CCAI and a 20-item demographic assessment form. A total of 245 students and alumni participated from two private Mennonite Colleges: Goshen College in Goshen, Indiana and Eastern Mennonite University in Harrisonburg, Virginia. These schools were chosen because of a strong emphasis on cross-cultural education across the curriculum; e.g., all EMU students are required to participate in a study abroad program and all Goshen students must either participate in a study abroad program or complete 12-13 hours of cross-cultural course work. Students/alumni were selected according to the following categories of previous cross-cultural experience: 
- no experience and no cross-cultural course work

- no experience and some cross-cultural course work

- length of experience ranging from 2 weeks to more than 1 year

- location of experience

- TESOL minors

Data were collected from the subjects only pre- or post-study abroad experience. Because the longest institutionally-organized study abroad experiences were four months, subjects who indicated longer experiences were those who went abroad either on their own or with other organizations.

Results of the study were analyzed quantitatively. Unlike Kelly and Meyers (1993), who used parametric tests for analysis, the present study considered Likert scale data to be ordinal (as opposed to interval) data and thus used parametric analysis only after ranking the raw data. To be conservative, nonparametric results were also reported. For parametric analysis, one-way Analysis of Variance (ANOVA) and the Pearson Product-Moment correlation coefficient were used. The Kruskal-Wallace one-way analysis of variance test and the Spearman correlation coefficient were the counterpart tests used for nonparametric measures. Scheffé's test, a conservative measure appropriate for unequal sample sizes, was run for significant ANOVA's as a way to test for significant differences between specific pairs of means. Because of the statistical methodology used in this study, results could not be compared to those of Kelley and Meyers in terms of standard scores.

\section{SUMMARY}

The present study took place in response to growing recognition of the interconnectedness of language and culture. Believing that cultural self- and otherawareness and sensitivity are especially critical for second language teachers, the study 
focused on study abroad experiences as a commonly assumed way of enhancing one's crosscultural adaptability. Other previous experience abroad and cross-cultural course work were taken into consideration as well. Data from 245 participants were collected by means of questionnaire and demographic items created to assess the relationship between crosscultural adaptability--the dependent variable--and four independent variables--host culture contact, cultural distance, language proficiency, and length of experience abroad. 


\section{CHAPTER II}

\section{REVIEW OF THE LITERATURE}

\section{INTRODUCTION}

The field of intercultural communication, arising from practical concerns expressed by participants in the Peace Corps, the military, missionaries, and other overseas sojourners (Wiseman \& Koester, 1993), has flourished in the past 40 to 50 years. The main impetus behind this growth is commonly attributed to an increase both in international politics and technology since World War II. Today, copious amounts of material in the field testify to ever growing recognition of intercultural communication as a discipline.

From its inception, however, clear conceptualization of intercultural communication theory has lagged behind practice (Damen, 1987; Dinges, 1983; Paige, 1986), creating a somewhat elusive and potentially daunting challenge to the neophyte intercultural researcher. Nineteen years ago when asked to speak on intercultural education, Kim stated:

Teachers and students of intercultural communication often experience frustration because of the lack of agreement in the definitions and conceptual framework of the area. The confusion stems partly from the newness of the field and the lack of sophisticated conceptualization. It is also due to the fact that the very nature of culture and communication, the two main constructs in intercultural communication, are so widely and deeply diffused into the wholeness of human life that they defy all attempts at unambiguous definition and declaration of concrete conceptual domain. (1979, p. 276)

Seventeen years later, Wiseman and Koester (1993) point toward a situation apparently much the same, stating, "There is a conceptual morass of models and perspectives toward competence of human relations....and a parallel fragmentation of methodologies and 
measurement approaches" (p.153). In the literature, this lack of clarity and resultant frustration appears on two intertwined levels: (1) the practical level, involving inconsistency of definition and use of fundamental terminology in the field and (2) the theoretical level, involving a myriad of conceptualizations for cross-cultural adaptability and/or effectiveness.

\section{Terminology}

Intercultural researchers invariably preface research discussions/results by acknowledging the common interchanging of terms such as intercultural (and/or crosscultural) adaptability, adjustment, success, competence, effectiveness, assimilation and acculturation (Damen, 1987; Dinges, 1983; Hannigan, 1990; Rohrlich \& Martin, 1991). The problem is not merely the intermixing of words but the fuzziness in constructs that this "terminology swapping" represents. It appears that many researchers respond to this by synthesizing various definitions of the chosen terminology into a definition of their own. The construct of "adaptability," the focus of this study, is an effective example of this. Hannigan (1990) views adaptation as encompassing cognitive, attitudinal, behavioral, and psychological changes which result in an individual moving from a state of discomfort to feeling at home in the new or foreign culture. Hansel and Grove (1986) define adaptability as the "ability to deal flexibly with and adjust to new people, places, and situations; willingness to change behavior patterns and opinions when influenced by others" (p. 86). Bennett lists adaptation as the fifth of six stages toward becoming ethnorelative. For Bennett (1993), adaptation is defined as an additive process (not implying assimilation) whereby "new skills appropriate to a new world view are acquired" (p. 52). And Juffer (1993), like many others, notes that she uses the terms "adaptation" and "adjustment" interchangeably. Unfortunately, specific definitions for other terminology in the field follow 
the same pattern of variation. Two of the few general consistencies noted are (1) a tendency to view adjustment as either interchangeable with adaptation or as a component of adaptation (Brislin, Landis, \& Brandt, 1983; Hannigan, 1990; Kelley \& Meyers, 1993;) and (2) a tendency to use the terms effectiveness, competence and success to discuss concrete contributing factors rather than the process of cross-cultural effectiveness (Kelley \& Meyers, 1993).

Ideally, the present study should primarily address literature focusing on crosscultural adaptability since the instrument used, the Cross-cultural Adaptability Inventory by Kelley and Meyers (1993), attempts to measure this specific construct. Unfortunately, it is extremely difficult to compare exactly across studies in the intercultural field because of the variation noted above. Adding to the difficulty, Kelly and Meyers themselves do not clearly claim an overarching definition of adaptability except as measured through their fourdimensional, 50-item inventory. The following review of the literature is therefore written with an attempt to focus on cross-cultural adaptability but with leeway given to including studies which may use varying terminology such as competence, success, and adjustment in ways closely relating to adaptability. In any case, a conscious choice was made to keep terminology consistent with the each researcher's original terminology in order to avoid misinterpretation.

\section{MODELS OF INTERCULTURAL EFFECTIVENESS}

With such variation in terminology, it is not surprising that there appears to be a concomitant variation in theoretical models of cross-cultural adaptation and/or effectiveness. Although researchers such as Dinges (1983) have made efforts to provide comparative frameworks for identifying intercultural models, theory within the field of intercultural 
communication remains diffuse. Because of this, it is impossible to give an exhaustive review of the literature in this area. Instead, the following briefly focuses on three approaches deemed representative of the diversity in the field. Trait theory, task/situational theory and Bennett's Model of Intercultural Competence are discussed in chronological order as they evolved in the field.

\section{Trait Models}

The most predominant models in the literature often focus on specific, isolated traits for measurement of cross-cultural effectiveness (Dinges, 1983; Kelley \& Meyers, 1993). For example, Hansel and Grove (1986) surveyed sojourner characteristics such as adaptability, critical thinking, independence, international awareness, self-confidence, and understanding other cultures. Carlson and Widaman (1988) studied international political concern, cross-culture interest, critical thinking and cultural cosmopolitanism. Others looked at world-mindedness, interpersonal flexibility, and non-materialism (Kauffman, Martin, and Weaver, 1992). The largest published group of this type of research is the often-cited Peace Corps Studies.

Variables that influence these traits are also commonly studied. These variables include such factors as gender, age, previous cross-cultural experience, length of crosscultural experience, cultural distance, language study and/or proficiency and location of cross-cultural experience. A common goal of many studies using this approach is to identify predictive variables of intercultural adaptability. The method of research in these models often revolves around self-report data.

\section{Task/Situational Theory--Performance-Based Competence}

The reverse of the trait theory approach is exemplified by Dinges (1983). Instead 
of pooling the definition of intercultural effectiveness from identified traits, Dinges first asks for a clear theory of intercultural effectiveness. From this theory of intercultural effectiveness--gathered from demonstrated and observed cross-cultural performance--one selects specific traits as predictors of cross-cultural effectiveness. The emphasis in this model is placed on analysis of specific tasks and situations within the cross-cultural experience. Dinges believes that "...competence is more appropriately inferred from a demonstrated behavior rather than the potential for behavior being inferred from a reported trait, knowledge area, or skill" (p.193). In other words, simply because one self-reports a given trait or set of knowledge does not mean that the outcome will be equivalent in behavior. Kealey and Rueben (1983) echo Dinges' caution.

Practically speaking, this would shift the focus of the intercultural selection and training processes to focus less on presumably important personal characteristics and more on task/situational factors in the intercultural setting. This in turn would lead to a greater emphasis on behavioral analysis in intercultural research. A major problem currently with this is a lack of clarity in intercultural effectiveness theory from which to begin.

\section{Bennett's Model of Intercultural Competence}

Unlike both of the above models, which search for variables and theory of predictive validity, Bennett's model of intercultural competence focuses on the process of intercultural effectiveness. Many researchers currently agree with this focus on intercultural effectiveness and adaptability as a process (Kauffman et al., 1992; Sikkema \& Niyekawa, 1987; Wiseman \& Koester, 1993). Bennett's particular model of intercultural competence involves six developmental stages framed by a paradigmatic shift from ethnocentrism to ethnorelativism, characterized by three stages in each. This model forms a process-oriented, culture-general 
(not focusing on a specific culture) theory of culture learning.

Ethnocentrism. Referring first to ethnocentrism in general as a "default stage," Bennett argues that our primary socialization naturally leads us to believe in the centrality of our own culture above others. The danger of this stage is that "other cultures become less truthful, less real, and perhaps the people who hold those cultures, less human" (Bennett, 1995). Stewart portrays a good example of this ethnocentrism:

When we travel in other cultures, we marvel at the credulity of others: their superstitions, numberologies, rituals, and magical beliefs. We discover "primitives" practicing mana. Our own practices, however, are assigned to a different category. We do not recognize the magical beliefs in technology, the faith we have in the objectivity of science, and our trust in quantification and measurement. (1979, p. 9)

Bennett's three stages of ethnocentrism are denial, defense, and minimization. He likens the first stage to the stage of denial found in addiction. In this stage, people do not acknowledge their state because they are unable to see things as different. Hoopes and Pusch discuss the same idea in slightly different terms asserting that our most powerful concepts of self which dictate our behavior are often hidden in a deeply buried inner level of awareness $(1979$, p.36).

A person in the second stage, the defensive stage, makes the important step of acknowledging differences but polarizes the differences into categories of good or bad. Usually a person in this stage denigrates one culture while holding the other up as superior. A person in the third stage--minimization--also accepts differences but subjects those differences to the (supposedly) greater importance of a common base of humanity; i.e., "...it is in the addressing of that deep commonality that we will find the ability to get along with one another" (Bennett, 1995). Bennett suggests, however, that each person unconsciously assumes that the deep commonality is a reflection of one's own self. 
Ethnorelativism. Following minimization, Bennett proposes a paradigm shift whereby people move from avoidance to acceptance of differences, or from the broad category of ethnocentrism to the category of ethnorelativism. The ethnorelative person understands that "cultures provide us with different organizations of reality" (Bennett, 1995). The first stage of ethnorelativism is acceptance, not of the goodness of difference, but merely the existence of difference. Moral judgment is not a part of this acknowledgment.

The second stage of ethnorelativism is adaptation, which Bennett defines as the development of "cultural empathy." This action of being able to "step imaginatively into another's world view" (Bennett, 1995) is a more important part of the process of learning than gaining discrete specifics about the culture itself, because once learned, the process is extensible to other cultures. Taylor (1994) speaks to the same idea when he talks of perspective transformation, where one's own world view is changed forever after being seen through the eyes of another culture.

Integration is the last stage and the final goal of intercultural communication, where identity is not dependent on one's primary association of culture. Rather, the interculturally competent person is "able to move in and out of other cultures" in a positive (and even mediatory) way described as "cultural marginality."

\section{RATIONALE FOR STUDY ABROAD}

Assuming acceptance of Bennett's paradigm shift, the question of how one travels toward ethnorelativity is immediately relevant. As with the present study, cross-cultural sojourns provide one of the most common resources for addressing this question. Before elaborating, it should be noted that several researchers such as Dinges (1983) and Klemp 
(1979) warn against overemphasizing the importance of experience abroad as a criterion for intercultural adaptation. Dinges begins and ends a chapter on intercultural competence speaking about an "inordinate amount of emphasis" placed on the effects of previous crosscultural experience. Decrying what he refers to as the "exposure-experience-expertise fallacy," he calls researchers to shift their focus from cultural exposure to behavior required for tasks in the intercultural environment. Damen (1987), though not invalidating the value of cross-cultural sojourns, also begins her book on intercultural learning with a caution to teachers against the assumption that cultural experience ensures cultural competence in the classroom. Simply put, both researchers appear to be sending the message that experience alone does not guarantee cross-cultural adaptability.

For the most part, however, it appears that researchers at least acknowledge a general validity of study abroad programs. Granting this general validity, a more controversial question asks specifically why some experiences are more successful than others in the growth of cross-cultural adaptability. The following focuses on this question, first by looking at the phenomenon of culture shock, then by addressing four variables commonly discussed in the literature: (1) host culture contact (2) cultural distance (3) second language proficiency and (4) length of experience abroad.

\section{Culture shock}

A review of the literature points to the role of culture shock as a potentially vital component of the developmental process of cross-cultural adaptability. First coined by Cora DuBois in 1951 and commonly cited after Oberg's use of the term in 1960, culture shock is by now defined in various ways. For example, Sikkema and Niyekawa (1987) view culture shock as: 
...the state of disorientation experienced by a person entering a new culture or subculture as he discovers for the first time that many of the things to which he is accustomed are unique to his own culture. The more culturebound he is, the greater the shock. (p. 6)

Furnham (1988) states that:

Many view culture shock as a stress reaction where salient psychological and physical rewards are generally uncertain and difficult to control or predict. Sojourners remain anxious, confused, and sometimes apathetic or angry until they have had time to develop a new set of assumptions that help them to understand and predict the behavior of others. (p. 46)

After studying more than thirty-five definitions of culture shock in the literature, Juffer (1993) categorized five basic causal factors for culture shock as briefly summarized below:

1. Confrontation of a new environment or situation. Culture shock is induced by the newness of a cross-cultural experience. Essentially all persons in a new cultural situation are expected to experience the effects of culture shock. Two classic stage theories, the U-Curve (Lysgaard, 1955) and W-curve (Gullahorn \& Gullahorn, 1963) theories of intercultural adjustment fall into this category. According to Ucurve theory, adaptation begins with an initial stage of euphoria, followed by a difficult downward swing representing culture shock, followed by a rise upward again--thus creating a U-shape. The W-curve is described as an extension of the Ucurve whereby returning sojourners experience the U-curve stages of culture shock both upon initial entry to a new culture and then a second time upon re-entry to one's home culture. The "second U" of re-entry is often referred to as "reverse" culture shock.

2. Ineffectiveness of intercultural or interpersonal communication. Culture shock is caused by a breakdown in interpersonal communication. 
3. Threat to the emotional or intrapsychic well-being of the sojourner. Culture shock is seen as an internal psychological failure to respond appropriately to vast differences in a new culture.

4. A need to modify behavior to regain positive reinforcement from the new environment. Culture shock is behaviorally explained as an effort to create a fit between behavior and anticipated consequences.

5. Growth experience. Culture shock is seen as "...a natural transition state that has potential for positive learning and growth" (p. 214).

As Juffer and other researchers in the field comment (Furnham, 1988; Sikkema and Niyekawa, 1987), the predominant use of the term culture shock is negative. It should be noted that of Juffer's five categorizations, only one points toward the potential for growth. Undeniably, culture shock is a difficult phenomenon to experience and for some individuals can be truly detrimental to the whole of their overseas experience. This viewpoint is easily found in a wide variety of the literature.

More difficult to find are the fragments of the literature which seem to suggest that it is, ironically, the very "upsetting" nature of culture shock that can give it its ultimate value. Sikkema and Niyekawa (1987) note that culture shock involves "being sufficiently shaken up to recognize that certain previously learned role behavior differentiations are not useful and must be ignored or forgotten in order to learn new ones" (p. 43). At the root of this viewpoint is the common acknowledgment that a first step toward cross-cultural adaptation is understanding one's own cultural perspective (Damen, 1987; Kelley \& Meyers, 1993; Paige, 1993). Paige (1993) describes the normal state of human nature as uncritical and unquestioning of one's own or others' cultural assumptions espousing the notion that a "jarring experience" is necessary to force "self-reflectiveness and self-awareness." Weaver 
(1993) assumes the analogy of transitional periods of human development noting that "As with growth or adaptation there is disorientation, ambiguity, and pain but we often come through this state more stable and centered than ever before" (p. 378).

\section{Passive vs Active Learning}

One of the underlying currents of focus on self-awareness is that culture shock reaches beyond cognitive boundaries to affective realms. Sikkema and Niyekawa (1987) discuss this in terms of passive vs active learning, stating that "The essential difference between passive and active understanding lies in intellectual and rational understanding on the one hand and affective or emotional understanding on the other" (p. 4). While passive (intellectual) understanding can easily be acquired without contact with other cultures, truly active (affective) learning is particularly difficult where most conscious learning takes place-in the classroom. Even though cultural material may be presented "the student does not experience the embarrassment of making mistakes or the joy of successfully functioning in another culture" (p. 4).

Active learning, then, strives for a level of inward awareness. Hoopes (1979) suggests that an inward level of cultural self-awareness can be reached best through appeal to the emotional experience rather than the intellectual idea--the affective vs the cognitive. Taylor (1994) also affirms this notion, referring to emotions as a "catalyst" for intercultural competence, especially in the culmination of a "disequilibrium experience" that jolts one into awareness. Wiseman and Koester (1993, p. 7) apply the term "visceral understanding" to this same concept.

It is important to note that, unlike reactions at the rational level, reactions at the emotional level are not usually under conscious control. Culture shock as part of active 
learning cannot be planned or scheduled by rational will. It is this active learning of the experience abroad that seems to carry the major impetus for promoting sojourns abroad.

\section{FOUR VARIABLES OF CROSS-CULTURAL ADAPTABILITY}

\section{$\underline{\text { Host Culture Contact }}$}

One of the first assumptions inherent in the espousal of study abroad experiences is meaningful contact with the host culture, specifically in terms of interpersonal relationships. This assumption is implicit in Sikkema and Niyekawa's (1987) assertion that active learning takes place "when people of different cultures or subcultures interact in face-to-face situations in which egos are involved" (p. 3). Others explicitly list contact with the host culture as necessary for cross-cultural adaptability ( Kauffman et al., 1992; Wiseman \& Koester, 1993). Kim (1988) views cultural contact as absolutely essential for adaptive cultural learning stating,

All adaptive cultural learning of sojourners takes place in the context of social communication...[and] relationships with host nationals serve as crucial social context from which strangers learn and participate in communication activities which in turn facilitate the development of host communication competence. (p. 249)

Brislin et al. (1983) speak of host culture contact as a means of challenging deep-rooted ideas leading to self-examination and self-growth. Klineburg and Hull (1979) found that social contact with local people of the host culture was one of the two most important coping processes in their study abroad research. Rohrlich and Martin (1991) found that a high level of interaction yielded a higher degree of satisfaction. Likewise, Kealey (1989) lists the two clearest characteristics of overseas success as strong interpersonal skills and social interest.

Kealey also states that although the most successful sojourners can generally be 
expected to interact more with the host country individuals, they can also be expected to undergo the most intense stress in adaptation. Paige (1993) underscores this statement asserting that most research indicates that greater immersion is more stressful but results in greater learning. This highlights the difficulty of defining success in experience abroad; i.e a so-called "negative" experience may eventually result in positive, or successful, learning

There is much variation, however, in the conduciveness of study abroad programs to host culture contact. Koester (1987) suggests that quality and quantity of host contact increase for students who are directly enrolled in foreign institutions or who work in the host culture. She attributes this to increased student responsibility for independently negotiating communication. Most likely for this same reason, many researchers view living with host families as vital to enhanced cultural learning. Although living with conationals can be valuable for lessening the effects of culture shock, it can also be a deterrent to likewise valuable contact with host nationals (Grisbacher, 1991).

There are a variety of reports about the outcome of host culture contact. For example, the following two studies show mixed results. Schwarzwald's 1983 study showed an increase in interpersonal acceptance but only for the persons with whom the subjects became acquainted. A study of 662 Jewish Israelis in Egypt chose an experimental group to be exposed to programs designed to positively influence Israeli perceptions of Egyptians (Amir \& Ben-Ari, 1983). Results showed a positive effect on the personal-social attitudes toward Egyptians but no change in political attitudes. More representative of clearly positive interaction results, interviews by Menanteau-Horta (1983) showed that high school seniors in Chile and Bolivia who had contacts from each other's culture were more accepting of people from other countries. 


\section{Cultural Distance}

A second potentially influencing variable in study abroad sojourns is cultural distance, or, the degree of "differentness" between cultures. Triandis (1993) describes cultural distance as most often visible through discrepancies in language and social structure, and political, economic, and religious systems. In the cross-cultural literature, cultural distance appears to be one of the less-often measured variables. An apparent lack of easily available instrumentation appears to be a contributing factor to this lack of measurement. Only two measurement tools appear with any consistency in the literature. The first is that of Bogardus (1925). Bogardus' test of social distance involves comparing varying degrees of acceptance of given choices; e.g., individuals may be asked whether they would be willing to live with, next to, or in the same neighborhood, city or country with individuals of a different racial group. The second is the Culture Distance Index, or CDI, created by Babiker, Cox and Miller (1980). Babiker et al. consider the CDI to be the first attempt at comparing and contrasting cultures, noting that Bogardus' Social Distance Scale measured only attitudes and prejudices. The CDI includes twelve parameters (such as climate, food, language, material comfort, religion, etc.); however, Babiker et al. acknowledge that these categories are arbitrary and nonexhaustive. To design the CDI, characteristics for the reference culture were first specified and a scoring system was established. Then, subjects were interviewed by two separate raters using predetermined questions related to the twelve parameters. The subjects with the highest score, or Cultural Distance Index, were considered the most culturally distant. As a result of their study, Babiker et al. suggested a direct connection between the degree of alienation, estrangement, and psychological stress and the distance between the students' own culture and the host culture. Also using the CDI, Furnham and Bochner (1986) found that the degree of difficulty experienced by 
sojourners was directly related to the cultural distance between the sojourners' culture and host society. Representative of much of the literature, both of these studies seem to focus on the negative aspects of increased cultural distance.

A smaller number of researchers list greater potential for learning through experience of increased adjustment demands created by greater cultural distance. Whether this learning is positive or negative, however, is unclear. Although the context of several research discussions seems to imply positive growth, the actual core statements remain more noncommittal. For example, Sikkema and Niyekawa (1987) encourage U.S. students to choose cross-cultural experiences with greater cultural distance but state only that "the choice of a non-Western culture as the second culture for the western learner will have a greater overall impact (p.18). Likewise, Kelley and Meyers (1993) insert, without further explanation, the possibility that their instrument for measuring cross-cultural adaptability may "become increasingly important the more the new culture differs from one's own" (p. 12). Paige (1993) discusses degree of cultural distance as the first of ten introductory hypotheses on intercultural education positing that "the greater the degree of cultural difference between the sojourner's own and the target culture, the greater the degree of psychological intensity" (p. 5). He then proceeds to point out that M. Bennett (in the same volume) emphasizes differences over similarities as necessary for the production of "challenging and stressful" intercultural experiences. What he avoids or neglects to address is the positive or negative directional outcome of the challenge.

A shortcoming of research in this area is that the history of U.S. study abroad students has traditionally centered primarily around western European countries. According to the 1989 Council on International Education Exchange (CIEE) National Mandate for Education Abroad, "At present more American Undergraduates study in the United 
Kingdom alone than the total of all in Asia, Africa, the Middle East and Latin America" (p. 6). Members of this committee listed "correction of the grossly disproportionate involvement of western European sites compared to all the rest of the world" (p. 6) as one of their major goals for the future.

\section{Second Language Proficiency}

Knowledge and use of host culture language is also a variable intertwined with host culture contact. Cicekdag (1987) cites as the underlying connection of language and culture, the idea that different languages embody different world views; e.g. depending on the language used, one event can be construed in two or more very different ways. Damen (1987) notes that language and culture learning each involve recognizing and obeying rules and patterns. Targeting language learning as a potentially critical factor for students, Koester comments,

Either the antecedent condition of second language learning or the experience itself of learning and functioning within the framework of the second language may be critical to the noticeably different impact these students identified. The language learning, then, is seen as a function of the host culture contact. (p.106)

This fits with the view of researchers such as Grisbacher (1991) and Paige (1993), who see language as a means to enhance social interaction and thus cultural adaptation. Specifically, Gudykunst and Hammer (1983) mention (1) understanding the host culture and (2) projecting a positive image of the sojourner's own culture as two integral reasons for language training as part of cross-cultural orientation. Pruit's (1978) study of 296 African students found that those with poorer host culture language skills did not adapt as well as those with better language skills. Day (1987) found that students on summer programs with lower host culture language levels were less likely to benefit from the educational 
opportunity (though he did not further define "benefit").

Other researchers do not point so clearly to language proficiency as a causal factor in positive cultural adaptation. Reviewing the literature compiled from Peace Corps studies, Dinges (1983) points out consistently low correlations between (1) language proficiency and job competence and (2) predeparture language proficiency and the prediction of overall intercultural effectiveness. Paige (1993) adds that language knowledge and use of host culture language are not always "absolutely essential" (p. 7) and do not guarantee effective communication.

Regardless of one's belief concerning adaptability and language proficiency, the notion that language learning on a cross-cultural sojourn is automatic is considered a misperception by most researchers. Engle (1987) puts it well commenting,

The romantic, subjective bent of American culture whispers to the young that tromping the streets of exotic cities equals learning. That is only partly true; those who learn most in the streets also put in the most serious time in the classroom and library and in learning the language of the country. (p.262)

The experience abroad is, however, often cited as inspiring interest in foreign languages. Armstrong, in his 1984 study, noted that the first item of student-perceived benefits of study abroad was becoming fluent in Spanish and developing a desire to continue in language study. In Hansel and Grove's (1986) study of high school students, those who went to English speaking countries scored lower on "Foreign language Appreciation and Ability" than those who went to non-English speaking countries. With pre- and post-test scores, students who did not participate in exchange programs dropped slightly in this category.

\section{Length of Previous Experience Abroad}

In general, although claims abound for the importance of the study abroad experience, not much empirical support is available for these claims (Carlson \& Widaman, 
1988; Koester, 1987). In particular, it appears that length of stay has received less purposefully focused attention than many other study abroad variables. In the first nationwide survey of U.S. students who study, travel, and work abroad, Koester (1987) noted that few researchers have specifically compared effects across types and lengths of experiences. What evidence has been collected, however, calls for attention due to the consistency of findings.

Study abroad experiences are commonly categorized according to time periods of one-month, one to three months, six to twelve months, one year or more, and school term or semester. The one-month time period and sometimes the summer term (or its equivalent) are usually referred to as "short" study abroad experiences. For those who specifically focus on length of stay, general consensus is that these shorter experiences are not as effective as longer experiences. Kauffman, Martin and Weaver (1992) summarize the findings of early researchers as indicating "minimal impact and few personal changes" (p. 62) for short stays abroad. Koester (1987) decisively reports that the six-to-twelve month period produces the greatest impact while the less than one month period produces the least impact.

In regard to length of stay, Bennett's model of intercultural communication suggests that those who spend less time in experiences abroad may simply not have had enough time to progress beyond the first stages of ethnocentrism. Grove (1983) says, "It requires time, repeated contact, and the sharing of a variety of experiences to get beyond what has been called the 'So nice to see you' phase of interpersonal relations" (p. 2). Sikkema (1977) notes that home stay on short sojourns can inhibit learning because of difficulty in getting out of the "guest role." The benefits that Day (1987) lists for short summer programs address only factors indirectly related (if at all) to enhanced intercultural communication such as greater prestige of the sponsoring institution, promotion of student recruitment into language 
courses, and travel benefits to faculty escorts.

An interesting finding across several studies at first seems contradictory to the stated negligible effects of short term experiences. In Martin's (1987) study of self-perceptions of intercultural competence, students with no previous overseas experience rated themselves fairly high overall in their intercultural communication abilities, and specifically rated themselves higher in their Awareness of Self and Cultural Norms than sojourners with some experience. In an American Field Service (AFS) study comparing short term (3-month) and year-long program experiences (using the same instrument for both), short term students showed significantly greater increases than year program students on Adaptability and Understanding Other Cultures (Hansel, 1986). Although Kelley and Meyers (1993) do not address this, their data indicate that sojourners with experiences of less than one month duration have higher mean ratings than sojourners with one to 12 months experience on two out of four of their cross-cultural adaptability subscales--Emotional Resilience and Perceptual Acuity.

These latter findings are particularly interesting, since intuition would suggest decreased rather than increased ratings for those with short term experiences. One possible explanation (related to Lysgaard's U-curve theory) is that short term experiences simply do not allow sojourners enough time to go through the stages of adaptation; i.e. sojourners return before ever leaving the euphoric stage. Grove (1983), a strong dissenter of one month or less short term cross-cultural programs, warns that "Such exchanges... hold little promise of accomplishing those high goals that most of us in the business of intercultural exchange hold dear" (p. 1). In his opinion, short term exchange programs run too great a risk of falling prey to Ross's (1977) "fundamental attribution error" in which individuals attribute behavior to personal traits and underestimate situational factors. Accordingly, 
... [these individuals] are likely to return to their home country with what they think is a rather well founded set of opinions about why their hosts act in the way they do. These opinions have a high probability of being trait attributions...This incomplete or erroneous information about the host nationals is all the more unfortunate because those who disseminate it are able to dignify it by their justified claim that "I know; I was there and saw it for myself." (Grove, 1983, p. 8)

Noting the high self-ratings of students in her own research, Martin (1987) made a similar comment noting that:

Resistance to intercultural training may be based on an assumption, on the part of the participants, that they are already competent in intercultural skills. This may reflect a more general feeling that intercultural skills are based on common sense, something at which most people are proficient. (p. 21)

These comments seem to point toward possible detrimental effects of short term cross-cultural experiences, specifically in the promotion of a false confidence in the participants' own intercultural competence and performance. Pearce's (1983) findings that individuals who had been on a three-week package tour "tended to be highly certain of the correctness of the stereotypes they held" (p. 29) would corroborate this possibility. According to these researchers, not only may stereotypes or preconceptions fail to be destroyed, but they may also actually be strengthened or encouraged.

Sikkema and Niyekawa (1987) agree that may people consider themselves competent in intercultural communication "without realizing how little they understand what they're doing" (p. 2). They add, however, that if study abroad programs are carefully designed and accompanied by effective predeparture and postreturn academic course work, a sojourn of two or three months can have an impact as great as, if not greater than, much longer programs. In as short as six to eight weeks, new perspectives emerged from participants in their program in Hawiaan, Chinese and Hong Kong cultures. Although not a focus of this study, many other researchers also emphasize pre- and post-field training 
(Kauffman et al., 1992; Martin, 1993; Sikkema and Niyekawa, 1987). A challenge for intercultural trainers thus seems to lie in planning not only for the experience itself but also for what surrounds the study abroad experience in a way that adds to the ultimate goal of maximizing positive change by the combined elements of cognitive, affective and behavioral intercultural learning.

\section{THE PRESENT AND FUTURE OF STUDY ABROAD}

Goodwin and Nacht's 1988 survey of approximately 40 U.S. colleges and universities showed great growth in current study abroad programs. In spite of the fact that governing boards of colleges and universities were supportive but usually not deeply interested in study abroad, the survey discovered no institutions (since the late 1980's) where the numbers of students studying abroad had declined. Although there remain a variety of commitments to education abroad, the future foretells only continued growth in this area (Mahan \& Stachowski, 1990; Allen, 1993; CIEE, 1990).

The goal of the European Regional Action Scheme for the Mobility of University Students is to raise the percentage of American undergraduates studying abroad for academic credit from a mere two percent to at least ten percent by 1992 (CIEE, 1990). The Council on International Educational Exchange (CIEE) recommends this for corporate dynamics as well as individual gain noting that the impact of substantial numbers who have studied abroad can produce a "multiplier effect" on home campus curricula and teaching.

\section{SUMMARY}

In the past 40 to 50 years, our increasingly mobile societies have inspired a likewise increasing number of international travelers, bringing concurrent growth in the field of 
intercultural studies. Due both to the relatively youthful status of the field and the inherent complexity of its subject, however, the intercultural field faces the considerable challenge of defining intercultural adaptability through a myriad of fluidly interacting variables. The variation in theoretical models of cross-cultural adaptation is also great. This chapter has discussed three differing models: trait model, task/situational model and Bennett's model of intercultural competence.

Assuming Bennett's model of cross-cultural adaptation as a process, this chapter has discussed culture shock as a crucial part of active learning and addressed four of many salient variables in the study abroad experience: contact with the host culture, cultural distance, second language proficiency, and length of stay. In short, to be effective, study abroad programs should at least ensure quality and quantity of contact with the host culture over a period greater than one month, preferably six to twelve months. Perspective transformation was viewed as a positive effect of culture shock with the idea that greater cultural distance may enable greater transformation. High language proficiency is often assumed to correlate positively with adaptation, though not all researchers agree.

Though some researchers such as Dinges (1983) seem to feel that past experience is held in too high an estimation for predicting adaptability, a greater number of researchers appear to lean toward the traditional view of study abroad sojourns as a potentially invaluable learning experience which often jolts students into greater self-and otherawareness. According to Goodwin (1988),

An educational experience overseas may be the best way to develop the culturally sensitive person at any level and anywhere. The full potential of this practice will be achieved only when study abroad can no longer even be conceived as a separate phenomenon, but is integrated fully within our conception of education. ( p. 118)

Regardless of differing viewpoints on the ultimate value of sojourn experiences, the future 
seems inescapably pointed toward increasing numbers of study abroad programs. Understanding and exploring the variables of cross-cultural adaptability in general, and in the study abroad experience specifically, should be of utmost importance to the TESOL profession in particular. As Damen (1987) states:

While cultural guidance is seldom part of the stated curriculum of the ESL, EFL, or any language classroom, it is nonetheless often a part of the hidden agenda, a pervasive but unrecognized dimension, coloring expectations, perceptions, reactions, teaching and learning strategies, and is more often than not, a contributing factor in the success or failure of second or foreign language learning and acquisition. (p. 4) 


\section{CHAPTER III}

\section{METHODOLOGY}

\section{SUBJECTS}

\section{$\underline{\text { Participants }}$}

Subjects for this study were selected from two private schools: (1) Eastern Mennonite University (EMU) in Harrisonburg, Virginia and (2) Goshen College (GC) in Goshen, Indiana. In each institution, the chairperson of the cross-cultural department served as the primary contact for this study from its inception till its close. These two individuals were pivotal in gaining the aid of the Registrar and Alumni Offices for selection information and assistance.

A convenience sample of 500 total students and alumni were chosen for the study-250 from each institution. Of the 500 surveys sent, 8 were returned with no forwarding address. Of the remaining 492 surveys, 245 were returned giving an overall response rate of approximately $50 \%$. Forty-eighty percent of the 245 responses were from EMU and $52 \%$ were from GC. All students/alumni selected had either graduated from or attended EMU or $\mathrm{GC}$ in the past three years. Although three years was used as a cut-off point, the majority of participants selected had graduated from or attended EMU or GC in the past year. Students/alumni were selected according to the following categories:

1. previous cross-cultural experience

- length of cross-cultural experience

- location of cross-cultural experience 
2. completion of alternate course work substituting for required cross-cultural experience

3. declaration of TESOL as an academic minor (TESOL was offered only as a minor at each school)

Subjects ranged in age from 18 to 54 with $88 \%$ between the ages of 18 and 24 . Approximately $1 / 3(84)$ of the participants were male and $2 / 3$ (161) were female. Approximately $32 \%$ considered themselves to be fluent in a second language, and $23 \%$ considered their parent/s to be fluent in a second language. Seventy-two percent had studied abroad through one of the institutionally-sponsored programs while $11 \%$ were granted exception from these programs because of prior experience abroad on their own (usually one year in length or longer). Forty percent had had previous experience abroad in addition to their study abroad experience.

The range of majors, minors, locations of experience and length of experience varied greatly. The 43 majors and minors listed were condensed into the following 8 categories: Arts \& Letters, Business, Education/Ministry, Languages, Liberal Arts, Social Sciences, and TESOL (see Appendix C). The 57 locations of cross-cultural experience were condensed into the following 6 general categories: Africa, Asia, Central America/South America/West Indies, Europe/Great Britain, Middle East, and North America (see Appendix D).

\section{Participating Institutions}

Both institutions participating in this study were church-school institutions affiliated with the Mennonite Church, a denomination of the larger Protestant Church. In some respects, the Mennonite Church could be considered a sub-culture of the North American mainstream culture. One of the tenets of the Church relevant to this study is an emphasis on service. Mennonites have long been active in relief, missionary, and volunteer work 
around the world. Because of this, students/alumni who are Mennonites or involved with Mennonite institutions may tend to have higher involvement and/or exposure to different cultures than is the norm for U.S. students. This cross-cultural emphasis is reflected in the institutional descriptions below.

Goshen College. In 1968, Goshen College became the first liberal arts college in the United States to incorporate study abroad as a required part of the school curriculum for all students (Gingerich, 1995). Since volunteer work was incorporated in the experience abroad, it was named "study/service term," or SST. Still today, students must either participate in a semester abroad, or an on-campus alternative consisting of (1) a prerequisite of two course units in any foreign language in college or two of a list of five designated cross-cultural courses and (2) twelve hours from a designated list of courses focusing on intercultural content. Any exceptions to the above must be approved by the dean of the college.

Although students can select from a variety of locations, all study-service terms follow a given format fairly consistently. Students spend the first seven weeks of the term studying language and culture of the target culture as a student group. The last six weeks are usually spent living with host families and experiencing greater interaction with the host culture.

Eastern Mennonite University. About 10 years ago, in 1986, EMU (then EMC-Eastern Mennonite College) also added a cross-cultural experiential component to their general education requirements. Although the intention and focus are much the same as GC's, EMU's cross-cultural options vary more in length and location. EMU offers crosscultural experiences ranging from $21 / 2$ weeks to a full semester (approximately 4 months). Unlike Goshen, EMU does not have a policy offering an already-established alternate course 
of study to replace study abroad. Students who do not go on a cross-cultural experience with EMU must submit a request for exemption. Usually, these requests are based on previous experience abroad or with other cultural groups in the United States.

\section{INSTRUMENT AND MATERIALS}

\section{Cross-Cultural Adaptability Inventory (CCAI)}

This study used a relatively new instrument, the Cross-Cultural Adaptability Inventory (CCAI) created by Kelley and Meyers, to determine self-perceptions of crosscultural adaptability. Although the CCAI was first developed in 1987, the present study used the latest version published in 1993. The CCAI is a culture-general inventory intended to measure universal qualities of adaptability as opposed to qualities specific to a given culture. The questionnaire contains 50 items rated by a 6-point Likert scale with the following categories:

Definitely True About Me

True About Me

Tends To Be True About Me

Tends Not To Be True About Me

Not True About Me

Definitely Not True About Me

Nine of the items are worded negatively to reduce response bias. Kelly and Myers (1993) clustered all 50 items into one of four dimensions of cross-cultural adaptability as follows:

Emotional Resilience (ER). This dimension has 18 items and is the largest of the 4 scales. Viewing culture shock and negative affect often associated with culture shock as a normal part of cross-cultural experiences, Kelly and Meyers designed this scale to:

assess the extent to which a person can self-regulate his or her emotions, maintain emotional equilibrium amidst a new or changing environment, and "bounce back" from and deal constructively with the setbacks and difficult feelings which are a normal part of the cross-cultural experience. (p. A-1) 
The 18 items are categorized into the following 4 dimensions:

"Coping, especially with stress and ambiguity"

"Rebounding from, and acceptance of, imperfections and mistakes"

"Trying new things and experiences"

"Interacting with people in new or unfamiliar situations"

Flexibility/Openness (FO). This scale has 15 items. In this dimension, Kelly and Myers focus on nonjudgmental attitude and flexibility of role behavior, noting that individuals with these two traits tend not only to be comfortable with, but also to enjoy cultural differences. Accordingly, this scale is designed to "assess the extent to which a person enjoys the different ways of thinking and behaving which are usually encountered in the cross-cultural experience" (p. A-5). The 15 items are grouped as follows:

"Liking for, openness toward, interest in, and desire to learn from, people and ideas different from oneself"

"Tolerance, nonjudgmentalness, and understanding toward others different from oneself'

"Flexibility with regard to experiences:

Perceptual Acuity (PAC). The 10 items in this scale focus on attention to, and accurate interpretation of, verbal and non-verbal communication across cultures. Individuals with high perceptual acuity are also seen as being sensitive to their own impact upon others. Kelly and Meyers do not categorize items in this dimension into further groupings.

Personal Autonomy (PA). The Personal Autonomy Scale focuses on one's sense of identity, identifying the adaptable individual as one who possesses a strong sense of selfidentity but who also remains sensitive to and values differences in others: 
The PA scale items assess the extent to which a person has evolved a personal system of values and beliefs which he or she feels comfortable and confident enough to act on amidst diversity. At the same time, the scale examines the extent to which this person respects others and their value systems. (p. A-11)

There were a total of 7 items clustered in this scale: The specific items were not further categorized.

Reliability and Validity of the CCAI. The CCAI evolved out of a need expressed by cross-cultural trainers and consultants for an easily obtainable instrument measuring culture-general adaptability. The authors state that it can be used by itself (as is the case in this study) but stress the effectiveness of using it as a part of cross-cultural training. As a self-awareness inventory, it is designed "both as a means of developing self-understanding in the area of cross-cultural adaptability, and as a take-off point for further awareness and skill training" (p. 1).

Because of their focus on self-assessment, the CCAI questions are designed to be easy to understand and thus tend to be transparent. The authors state that emphasizing the importance of understanding one's relative strengths and weaknesses rather than one's total score, should help deter participants from elevating their scores. However, Kelley and Meyers note that even if scores are elevated, the relative position of those scores should not change; i.e. people who tend to score high on one question tend to score high on related questions and vice versa. This is indicated by their standardized alpha (individual scale reliability) estimates as follows: Total $\mathrm{Score}=.90, \mathrm{ER}=.82, \mathrm{FO}=.80, \mathrm{PAC}=.78$, and $\mathrm{PA}$ $=.68$. The Pearson Product-Moment correlation coefficients among scales and total scores are as follows: $\mathrm{ER}=.87, \mathrm{FO}=.84, \mathrm{PAC}=.77, \mathrm{PA}=.55$.

In order to construct a valid instrument, Kelley and Meyers created the CCAI by gathering and comparing input both from the literature and from 25 individuals who had 
either (a) cross-cultural knowledge or (b) previous cross-cultural experience. Only items containing what were considered core aspects of cross-cultural adaptability were included. In addition, only dimensions that were considered difficult to measure were included; i.e., no questions directly addressing length of stay, language proficiency, etc. were included.

Traits were first listed by the 25 cross-cultural specialists, then compared with those cited in the literature and statistically analyzed. From sixteen of the most consistently highrated items, four clusters were created and confirmed by four separate judges. A fifth category was added to reflect agreement between the literature and experts on another skill set which also received high marks. Following this, 10 questions created for each category were tested by panels of cross-cultural experts and interested members of the public. Three revisions resulted from this testing and feedback, the last of which was presented at the SIETAR Conference (International Society for Intercultural Education Training And Research) in Montreal in 1987. Results of this first version were collected from 653 participants and statistically analyzed. The second version resulted from the deletion of the fifth skill set (determined to be a subset of one of the first four) and the shifting of several questions from one category to another. In 1989, this new version was again presented at the SIETAR conference. The current 1993 version is the final result of six additional item shifts emerging from new statistical techniques.

Predictive validity of the CCAI is not clear. On the one hand, Kelley and Meyers caution that the CCAI is intended to be a self-selection instrument as opposed to a selection instrument and is, therefore, not to be used to predict cross-cultural success or failure (p.12). On the other hand, however, Kelley and Meyers state only a few pages later that "Because of the methods used in [the CCAI's] construction, it is reasonable to expect that the CCAI would have some predictive validity" (p. 32). 


\section{Demographic Questionnaire}

A study such as this inevitably reaches a tension between adequately addressing all pertinent variables on the one hand and overextending to the point of unwieldiness on the other hand. Length of the demographic questionnaire, though not necessarily the ideal determinant, ended up providing the practical guideline for this tension. Two factors-expediency of completion for the subjects and cost for the researcher--pointed toward the goal of no more than one page in length (front and back). The goal for time needed to complete the total survey was 30 minutes maximum. The ultimate cost goal was $\$ .64$ per subject--\$.32 for the return envelope and $\$ .32$ for first-class mailing.

The demographic questionnaire evolved to a total of 20 questions (see Appendix B). The questionnaire was exactly the same for subjects from each institution with the exception of specific reference to EMU or GC and the terminology used for study abroad experience-"Cross-Cultural Seminar or CCS" for EMU and "Study Service Term, or SST" for Goshen. Data could easily be identified with the appropriate institution because of this. The four primary variables of interest in this study were (1) host culture contact, (2) cultural distance, (3) second language proficiency, and (4) length of previous experience abroad. These variables were addressed by the specific demographic questions as follows: (Note: Items listed below are not necessarily shown in exact format. See Appendix B.)

Host Culture Contact. Grisbacher (1991), after doing an extensive literature review on the effects of host and conational interaction upon student sojourner adjustment, concludes that increased meaningful interaction with the host culture appears to enhance sojourner adjustment. He also states that primary social interaction with conationals seems to result in a correspondingly poorer adjustment for sojourners. Item \#13 is an indirect measure of this, based on the assumption that host culture interaction increases by default 
as one moves from high to low contact with conationals as reflected in options (a) - (c) below. Koester (1987) asked a variation of this question in her survey of International ID card holders: "While out of the country will you be primarily (1) alone; (2) with one-three people; (3) with a group" (p. 119). However, because mere physical proximity, while important, can still result in varying amounts of host culture interaction, Item \#14 was designed as a direct measure of contact. Item \#19 was based on the intuitive assumption of a high likelihood that meaningful interaction would preclude efforts to keep in contact with host culture individuals.

Item \#13) What were your living arrangements while on your SST? (More than one option below may apply.)

[a] dormitory or motel/hotel with American group

[b] host culture family with another study abroad student(s)

[c] host culture family by yourself

[d] other

Item \#14) What percentage of your total SST time was spent interacting with members of the host culture?

(approximately)

Item \#19) How much contact do you currently maintain with individuals whom you met while on an SST?

Cultural Distance. Cultural distance was the most difficult variable to measure in terms of creating adequate demographic questions. In the literature review, most researchers determined cultural distance by eliciting and comparing perspectives of both the home and the host culture (Babiker, Cox, and Miller, 1980; Szalay and Maday, 1983). Since the present study obviously could not elicit perspectives from the varying host cultures, it was necessary to rely only on the subjects' self-perceptions of cultural distance. Ultimately, this determination of cultural distance was seen as the most ideal elicitation method since general categorizations of home and host cultures may not have captured individual differences in perspective as adequately. Intuition would suggest that American 
students would view the Middle East, for example, as more distant than Germany. Item \#17 allowed the student to make this judgment, however, instead of the researcher. Item \#8, location, could then be compared to perceptions of cultural distance in Item $\# 17$ as verification or disqualification of the researchers' intuition. The belief that greater cultural distance encourages greater cross-cultural learning seems to be based on an assumption that the increase in learning is a result of an underlying factor of increased adjustment demands. To address this, Item \#10 and Item \#11 elicited self-perceptions of adjustment during and immediately after the experience abroad.

Item \#8) Where did you go for your SST?

Item \#17) On the following items, compare/contrast your experience in the host culture with your experience in your own culture by circling a number from $1<-$-very similar to --> very different 6
a) Food
b) Concept of Time
a) 123456
c) Social Life
b) 123456
d) Religion
c) 123456
e) Economy
d) 123456
f) Political Stability
e) 123456
g) Ethnicity/Race
f) 123456
h) OVERALL Culture
g) 123456
h) 123456

Second Language Proficiency. This variable was comparatively straightforward. Both Item \#4 and Item \#15 were asked since students/alumni may have been fluent in a language different from that of the host culture during the study abroad. Subjects who considered themselves low-level host culture language speakers but who were fluent in another language may still have acquired culture-general linguistic skills, possibly affecting their adaptability rating. Item \#15 was asked based on Koester's (1987) study which suggested a possible positive relationship between sojourners' confidence in language abilities and parental international residence and fluency. More questions in this regard were 
not asked simply because of limited space.

Item \#4) Do you consider yourself fluent (or fully conversant) in any language(s) besides English?

[] no

[] yes

Which language(s)

Item \#5) Do you consider your parent(s) fluent (or fully conversant) in any language(s) besides English?

[ ] no

[ ] yes

Which language(s)

Item \#15) What was the primary language of the host culture during your SST and your skill level in that language?

(None) 123456 (Fluent)

Length of Stay. Item \#6 was intended to elicit length of stay specifically for study abroad experience. It seemed unjustifiable, however, to address only structured study abroad experience in light of the increasing incidence of "repeat sojourners." Item \#9 encouraged respondents to report up to three previous sojourns, providing location, time (how long ago), and length of previous experience.

Item \#6) Have you gone on a Study-Service Term (SST) with Goshen?

[ ] no

For how long? _ years _ months _ weeks

Item \#9) Have you had any other experience/s living abroad or with cultures other than your own?

[] yes

City, Country

From to

1.

2.

3.

Other Variables. For the most part, the remaining items and their corresponding variables are self-explanatory. Item \#1, Item \#2, and Item \#3 elicited age, gender, and major/minor respectively. Item \#12 measured satisfaction with experience abroad. Item 
\#18 elicited previous cross-cultural course work. This enabled the researcher to identify those sojourners not only lacking in experience abroad but also lacking in structured course work as well. Item \#20 was added as a standard way of allowing unstructured participant response to the survey for comments and/or clarification.

\section{Form Letter}

A one-page form letter introduced the researcher and the study, indicated validity of the referral sources by including the names of the cross-cultural chairpersons, assured confidentiality of responses, and provided information for further contact with the researcher. The form letter differed between the institutions only in order of institutional reference; i.e. for Goshen students/alumni, Goshen College was mentioned first and vice versa for EMU. Individualized inside addresses were included and the researcher wrote by hand each participant's name in the salutation as well as her own in the complimentary closing.

\section{Materials Included for High Return}

Self-Addressed, Stamped Enveloped. Including self-addressed, stamped envelopes doubled the cost of the present study but was deemed worth the likely resultant increase in response rate.

Gum. Each subject received a stick of "Extra" brand gum corresponding to the P.S. on the form letter which read, "Thanks for your extra time and effort!" This was also designed to increase response rate by personalizing the letter.

\section{PROCEDURES}

Surveys were mailed to one of two places: campus mailboxes or home addresses. 
To decrease postage, all subjects who were identified as current students received the survey through campus mail. Subjects received the following materials (as described above):

Introductory form letter 20-item demographic survey

50-item Cross-Cultural Adaptability Inventory

Self-addressed, stamped envelope

One piece of "Extra" gum

Participants had two to three weeks to respond to the survey. (A few had one week or less due to forwarding addresses.) The mailing was deliberately timed to avoid reaching students during or immediately surrounding midterms. A two-week average response time was allowed based on the rationale that a shorter length of time did not allow enough leeway for participation while a longer time may have encouraged procrastination and perhaps, ultimately, no response.

\section{Pilot Study}

A pilot study was conducted three weeks prior to mailing the questionnaires for data collection. Of the eleven people contacted, eight participated. In addition to these eight, responses/suggestions were solicited from both chairpersons of the cross-cultural departments. Subjects in the pilot study were asked to (a) record response times for both the demographic survey and the CCAI, (b) make a written note of confusing items, (c) give suggestions for improvement and (d) note any other reactions/responses. The Demographic information took an average of 11.5 minutes to complete while the CCAI averaged 14.8 minutes to complete. The pilot study resulted in the elimination of one question from the Demographic survey, the rewording of five questions and the reordering of two questions. It also resulted in a change of format to allow more room for additional comments. 


\section{DATA ANALYSIS}

It should be noted from the outset that the data analysis of the present study differed from that used by the authors of the CCAI, with the fundamental difference lying in the classification of the data. Like many researchers who employ Likert scales, Kelley and Meyers used parametric statistical tests (ANOVA and Pearson Product-Moment Correlations) for analysis. Since parametric tests are not intended to be used with ordinal data, the assumption is that Kelley and Meyers treated their Likert scale data as interval level data. The six specific options of the scale were: Definitely True..., True..., Tends to Be True..., Tends Not to Be True..., Not True.., Definitely Not True About Me Right Now. By assigning absolute values of 1 through 6 to these options, Kelley and Meyers treated the distance between "Definitely True" and "True" as equidistant to the distance between "Tends to Be True" and "Tends Not to Be True," etc. The present study maintains that it is not possible to claim equidistance in this scale or in Likert scales in general and, therefore, treats CCAI data as ordinal rather than interval level data.

Since the statistical methodology in this study differed from that of Kelley and Meyers from the start, it is only logical that the ensuing analyses should have followed a different route. The first step in this study involved identifying appropriate nonparametric measures for the ordinal CCAI data. Because of the CCAI's dependence on summing items for the four dimensions and for the total score, analysis of the resulting data required a method that would allow composite scores (of multiple variables) for each subject. Since standard nonparametric procedures do not allow for this, however, the present study created its own methodology using an adaptation of basic methodology that is followed in many nonparametric tests (such as the Kruskal-Wallace one-way analysis of variance, Spearman's 
correlation coefficient, Kendall's tau, Friedman's two-way analysis of variance, the MannWhitney U Test, and the Moses Test of Extreme Reaction) (SPSS Manual, 1992). The first step in all of these tests involves ranking each variable of the raw data and then comparing ranks. The problem of ordinality was likewise addressed in this study by first creating a program to rank the original raw scores $(1-6)$ for each item $(\mathrm{N}=50)$. The individual dimensions were then calculated by summing the ranks (rather than the raw scores) for the appropriate items in each scale. (The inevitably large number of ties were given "the arithmetic mean of the scores [ranks] that would have been received had there been no ties" (Blalock, 1972, p. 416).) Because rank is not affected by the non-linearity of data, the use of ranks in this manner avoided skewness potentially found in the original raw data distributions. Standard parametric procedures were then used upon the ranks as opposed to the raw scores (1-6). With respect to using parametric tests upon ranked data, it should be noted that the Spearman correlation coefficient is an example of a nonparametric test that does just this. Quoting from the SPSS/PC+ Manual (Version 5.0) regarding the methodology of the Spearman correlation coefficient, "For all cases, the values of each of the variables are ranked from smallest to largest, and the Pearson correlation coefficient is computed on the ranks" (Norusis, 1992, p. 198). Based on this understanding, for comparative purposes the present study ran two tests: (1) Pearson's correlation coefficient test using the already-calculated rank CCAI scores and (2) Spearman's correlation coefficient using the raw (1-6 value) CCAI scores for each of the 50 questions in the CCAI. As predicted, results from the two tests were identical to the fourth decimal place (as specified). This verified the accuracy of the methodology used in this study to rank the raw CCAI data.

The creation of an index, the problem of missing values, and weighting of items and 
dimensions were specifically addressed as follows. In order to simplify interpretation of results, an index was created with a value between 0 and 1 for the individual variables, the four dimensions and the total score. For each of the 50 variables for $\mathrm{N}=245$ subjects, the index was determined by dividing each subject's rank score by the total number of valid observations for that particular variable. Missing values were considered invalid observations. To calculate each dimension's score for each subject, indexes for all variables assigned to each respective dimension were summed and then divided by the total number of valid indexes for that particular dimension. Again, missing index values were considered invalid observations. In the first calculation above, missing values for a variable across subjects were accounted for while in the second calculation, missing values within subjects (within dimensions) were accounted for so that neither missing values for a variable nor missing values for an index in a dimension were allowed to weight resulting scores. The above methodology not only accounted for missing values but also accounted for differing numbers of questions comprising each dimension, thereby weighting each dimension equally.

The last step in assigning rank scores to the raw data was calculating a total CCAI score for each subject. Kelley and Meyers simply added all raw scores (1-6) for each of the 50 items. Their methodology resulted in scores that (1) risked skewness due to the nonlinearity of the Likert scale items and (2) were influenced by differential weighting of the four dimensions. It seems that Kelley and Meyers explicitly indicated unequal weighting of the four dimensions through their analyses but implicitly indicated equal weighting through their emphasis on comparing relative strengths and weaknesses of each dimension. The present study followed Kelley and Meyers' implicit indication of equal weighting by adding the four equally weighted dimensions (described above) together and dividing by four, instead of either simply (1) summing the raw scores for all variables 1-50 or (2) summing 
the indexes for all ranked variables 1-50.

At this point, parametric analyses could be run on the composite ranks of the four dimensions and the total score. One-way analysis of variance (ANOVA) was used to test for the difference of means, and Pearson's correlation coefficient was used to test for significance correlations between CCAI ranks and the independent variables. For comparative measures, nonparametric equivalencies--the Kruskal-Wallace Sum of Ranks test and Spearman's Correlation Coefficient-- were also calculated (still using the rank scores) and shown in the results. In addition, Scheffé's test of means was run on all significant ANOVA's to identify specific pairs of significant means. Scheffé's test is a conservative test especially appropriate for groups of unequal sample size. All Scheffé tests were run at the .05 level of significance. 


\section{CHAPTER IV}

\section{RESULTS}

\section{INTRODUCTION}

The purpose of this study was to statistically examine the effect of four independent variables--(1) host culture contact, (2) cultural distance, (3) second language proficiency, and (4) length of sojourn/s-upon the dependent variable of cross-cultural adaptability. The four corresponding research questions were as follows:

1. Is there a significant relationship between host culture contact during previous experience abroad and self-perceptions of cross-cultural adaptability?

2. Is there a significant relationship between cultural distance of previous study abroad experience and self-perceptions of cross-cultural adaptability?

3. Is there a significant relationship between second language proficiency and selfperceptions of cross-cultural adaptability?

4. Is there a significant relationship between length of previous study abroad experience and self-perceptions of cross-cultural adaptability?

Data for the independent variables were gathered from a 20-question demographic survey created by the author of the present study. The construct of cross-cultural adaptability was measured by the Cross-Cultural Adaptability Inventory (CCAI) created by Kelley and Meyers (1993). The CCAI is a Likert-scale inventory ranging from 1-6 (Definitely True About Me Right Now to Definitely Not True About Me Right Now) and is composed of 50 questions divided into four dimensions: Emotional Resilience (ER), Flexibility/Openness (FO), Perceptual Acuity (PAC), and Personal Autonomy (PA). These four dimensions together create a total score (TOTAL) for each subject. 
The authors of three dissertations (Field, 1990; Goldstein, 1992; Verne, 1991) quoted by Kelley and Meyers (1993) as using the CCAI, along with Kelley and Meyers themselves, used parametric statistical tests (ANOVA and Pearson Product-Moment Correlation) to analyze their raw data. The present study determined that parametric analysis on the raw CCAI data was inappropriate due to the ordinality of the Likert-scale data (see Chapter III, pp. 44-47 for further explanation). The following results are thus based not directly on the original raw scores (1-6) for each question but rather on the rank scores for each question and the composite rank scores for each CCAI scale and total score. In order to clearly mark this distinction in the following results, a capital " $R$ " representing "Rank" prefaces each of the scale and total score abbreviations listed above; i.e., ER=RER, $\mathrm{FO}=\mathrm{RFO}, \mathrm{PAC}=\mathrm{RPAC}, \mathrm{PA}=\mathrm{RPA}, \mathrm{TOTAL}=\mathrm{RTOTAL}$. Only after rank scores were obtained were parametric analyses run on the data. Nonparametric equivalencies were also determined as a conservative measure (still using the rank scores) and shown for comparative purposes in the results. One-way Analysis of Variance (ANOVA) and Pearson's Product-Moment Coefficient (r) were paired respectively with the KruskalWallace Sum of Ranks test and Spearman's Correlation Coefficient. Scheffé's test of means was run on all significant ANOVA's to identify specific pairs of significant means. Scheffé's test is a conservative test especially appropriate for groups of unequal sample size. All Scheffé tests were run at the .05 level of significance. Only means, F Probabilities (ANOVA) and H Probabilities (Kruskal-Wallace) are shown along with a general review of demographic items used to elicit data for each question. (Chapter III should be consulted for a detailed look at the demographic survey and the CCAI.)

Results of the statistical analyses are presented below in three main sections. The first section addresses the four primary research questions listed above. The second section 
looks at results specifically dealing with a subgroup of 28 subjects with academic minors in TESOL. The third section presents results also addressed by Kelley and Meyers--gender, age, and satisfaction with study abroad experience. Before the first section, however, the following gives a brief description of the CCAI correlations between the four scale ranks and total score ranks.

TABLE I

CCAI PEARSON AND SPEARMAN PRODUCT-MOMENT CORRELATIONS (r's) AMONG SCALE AND TOTAL SCORE RANKS

$$
N=245
$$

\begin{tabular}{lllll}
\hline & RFO & RPAC & RPA & RTOTAL \\
\hline RER & $.6953^{* *}$ & $.4980^{* *}$ & $.3999^{* *}$ & $.8568^{* *}$ \\
(18 items) & $.6641^{* *}$ & $.4650^{* *}$ & $.3985^{* *}$ & $.8442^{* *}$ \\
RFO & & $.5793^{* *}$ & $.2293^{* *}$ & $.8286^{* *}$ \\
(15 items) & & $.5643^{* *}$ & $.2275^{* *}$ & $.8182^{* *}$ \\
RPAC & & & $.1905^{* *}$ & $.7600^{* *}$ \\
(10 items) & & & $.1939^{* *}$ & $.7374^{* *}$ \\
RPA & & & & $.5845^{* *}$ \\
(7 items) & & & & $.5769^{* *}$ \\
\hline
\end{tabular}

${ }^{*} \mathrm{p}<.05 \quad$ Pearson correlation coefficient $=$ top number

$* * \mathrm{p}<.01 \quad$ Spearman correlation coefficient $=$ bottom number

As TABLE I shows, all possible correlations between the four CCAI scale rank scores and total rank scores $(\mathrm{N}=245)$ are statistically significant at the .01 level. These results are similar to those reported by Kelley and Meyers (1993) in their study of 653 subjects where RER had the highest and RPA had the lowest correlation coefficients with all other scales and total scores. It is interesting to note that the strength of correlation of each scale with RTOTAL scores seems to correspond with the number of items composing each scale; i.e., the order from highest to lowest, RER --> RFO-->RPAC-->RPA, is the same both for the number of items in a scale and for the strength of correlation with 
RTOTAL. Also, this is the first of several observations where RPA seems to stand out for having a low probability of significance.

\section{RESEARCH QUESTIONS}

Question 1- Host Culture Contact: Is there a significant relationship between host culture contact during previous experience abroad and self-perceptions of cross-cultural adaptability?

To answer this question, subjects were asked to (1) rate themselves for percentage of total sojoum time spent interacting with members of the host culture and (2) to indicate living arrangements while abroad. Subjects who responded to the question of living arrangements were separated into two groups: those who lived in a dorm or motel/hotel for the majority of the sojourn and those who lived with a host family either alone or with another study abroad student for the majority of the sojourn. The assumption was that those who lived with host families would have more, as well as more meaningful, interaction with members of the host culture. Correlational tests, as shown in Table II were run on the first item, and ANOVA's, as shown in Table III were run on the second. Both Table II and Table III indicate affirmation for Question 1 for all CCAI dimensions except for RPA. These results suggest that those who have had a higher percentage of interaction with the host culture and those who have spent more time living with host culture families perceive themselves to be more culturally adaptable except in the dimension of Personal Autonomy. It is thus not surprising that the group who lived in dorms/motels/hotels reported a mean percentage of approximately 45 for interaction while those who lived with host families reported a mean percentage of approximately 70 . The difference in these percentage means was significant at the .01 level (F Probability $=.0000)$. 
TABLE II

CORRELATIONS OF PERCENTAGE OF HOST CULTURE INTERACTION WITH CCAI SCALE AND TOTAL RANKS

$$
N=178
$$

\begin{tabular}{lccccc}
\hline & RER & RFO & RPAC & RPA & RTOTAL \\
\hline PERCENT & $.3160^{* *}$ & $.2922^{* *}$ & $.3045^{* *}$ & .1212 & $.3451^{* *}$ \\
CONTACT & $.2957^{*}$ & $.2711^{* *}$ & $.2716^{* *}$ & .1120 & $.3030^{* *}$ \\
\hline
\end{tabular}

$* \mathrm{p}<.05$

$* * \mathrm{p}<.01$
Pearson correlation coefficient $=$ top number

Spearman correlation coefficient $=$ bottom number

TABLE III

MEANS, F PROBABILITIES, AND H PROBABILITIES FOR CCAI SCALE AND TOTAL RANKS FOR SOJOURNERS LIVING IN DORMS/HOTELS AND SOJOURNERS LIVING WITH HOST FAMILIES

\begin{tabular}{lcccccc}
\hline GROUPS & N & RER & RFO & RPAC & RPA & RTOTAL \\
\hline Dorm & 65 & .4758 & .4854 & .4792 & .4795 & .4800 \\
Host Family & 83 & .5272 & .5286 & .5309 & .5036 & .5226 \\
\hline F Prob. & & $.0243^{*}$ & $.0462^{*}$ & $.0350^{*}$ & .2621 & $.0120^{*}$ \\
H Prob. & & $.0133^{*}$ & $.0415^{*}$ & $.0268^{*}$ & .3321 & $.0122^{*}$ \\
\hline
\end{tabular}

$* \mathrm{p}<.05$

$* * \mathrm{p}<.01$

Question 2 - Cultural Distance: Is there a significant relationship between sojourner perception of host culture distance and self-perceptions of cross-cultural adaptability?

This research question was actually addressed in two ways. The straightforward part of the question simply asked whether there is a connection between sojourners' selfperceptions of cross-cultural adaptability and their perceptions of the degree of "differentness" between their own and the host culture. Underlying this question, however, was a more fundamental one raised in the literature review which deals with difficulty of 
sojourner adjustment. The possibility raised by several researchers is that greater cultural distance requires greater adjustment with the implication that greater cross-cultural learning may thus ensue. Two demographic items, location and perceived cultural distance between home and host culture on 7 items (rated from $1-6$ : very similar to very different), addressed the first "surface" question of cultural distance. A weak relationship was found between RPAC and perceived cultural distance as shown in Table IV. No significant difference of CCAI means were found for location.

\section{TABLE IV}

CORRELATIONS @F PERCEIVED CULTURAL DISTANCE WITH CCAI SCALE AND TOTAL RANKS

$$
N=178
$$

\begin{tabular}{llllll}
\hline & RER & RFO & RPAC & RPA & RTOTAL \\
\hline CULTURAL & .1086 & .1189 & $.1471^{*}$ & -.0524 & .1096 \\
DISTANCE & .1084 & .1113 & $.1567^{* *}$ & -.0409 & $.1148^{*}$ \\
\hline${ }^{*} p<.05$ & Pearson correlation coefficient $=$ top number \\
${ }^{* *} \mathrm{p}<.01$ & \multicolumn{5}{l}{ Spearman correlation coefficient $=$ bottom number }
\end{tabular}

The second, underlying question, regarding difficulty of adjustment, was addressed by asking the sojourners to rate themselves on the difficulty of adjustment experienced first during the sojourn, then after the sojourn. Subjects were asked to respond using a scale of 1 - 5 (Not At All Difficult to Very Difficult). According to the results in Table V, CCAI means differed significantly for RER, RPA and RTOTAL for the 5 levels of adjustment during subjects' sojourns abroad. Table VI revealed no significant difference in means for levels of adjustment after subjects returned from their experiences abroad. Comparison of the highest and lowest means from both tables, however, seems to merit some attention. In Table V (adjustment during sojourn), the "Not At All Difficult" group had the highest 
mean for each scale and TOTAL while those who found adjustment "Very Difficult" had the lowest mean. In Table VI, results for those who found adjustment "Very Difficult" after their return took a dramatic turn from having the lowest means to having the highest means. RPA was the only scale which did not follow this switch from low to high means. Quite to the contrary, RPA means followed in a very orderly fashion from the highest mean/"Not At All Difficult" to the lowest mean/"Very Difficult."

TABLE V

MEANS, F PROBABILITIES, AND H PROBABILITIES FOR CCAI SCALE AND TOTAL RANKS FOR ADJUSTMENT DURING EXPERIENCE ABROAD

\begin{tabular}{lcccccc}
\hline $\begin{array}{l}\text { LEVEL of } \\
\text { ADJUSTMENT }\end{array}$ & N & RER & RFO & RPAC & RPA & RTOTAL \\
\hline $\begin{array}{l}\text { Not At All } \\
\text { Difficult }\end{array}$ & 14 & .6413 & .5650 & .4929 & .5936 & .5732 \\
Not Very Difficult & 84 & .5231 & .5259 & .5248 & .5018 & .5189 \\
Somewhat & 85 & .4971 & .4921 & .4911 & .4771 & .4894 \\
Difficult & & & & & & \\
Difficult & 13 & .4776 & .5033 & .5479 & .4982 & .5067 \\
Very Difficult & 8 & .3257 & .4237 & .4455 & .4639 & .4147 \\
\hline $\begin{array}{l}\text { F Prob. } \\
\text { H Prob. }\end{array}$ & & $.0000^{* *}$ & .0749 & .3230 & $.0298^{*}$ & $.0036^{* *}$ \\
\hline
\end{tabular}

$* \mathrm{p}<.05$

** $\mathrm{p}<.01$

Scheffé Results

\section{RER}

Not At All Difficult >

Very Difficult

Difficult

Somewhat Difficult

Not Very Difficult >

Somewhat Difficult >
Very Difficult

Very Difficult

\section{RPA}

Not At All Difficult > Somewhat Difficult

RTOTAL

Not At All Difficult > Very Difficult 
TABLE VI

MEANS, F PROBABILITIES, AND H PROBABILITIES FOR CCAI SCALE AND TOTAL RANKS FOR ADJUSTMENT AFTER EXPERIENCE ABROAD

\begin{tabular}{lcccccc}
\hline $\begin{array}{l}\text { LEVEL of } \\
\text { ADJUSTMENT }\end{array}$ & N & RER & RFO & RPAC & RPA & RTOTAL \\
\hline Not At All Difficult & 33 & .5309 & .5053 & .4948 & .5148 & .5114 \\
Not Very Difficult & 60 & .4863 & .4785 & .4707 & .5015 & .4842 \\
Somewhat Difficult & 49 & .4992 & .5012 & .5219 & .4956 & .5045 \\
Difficult & 23 & .5073 & .5082 & .5024 & .4720 & .4975 \\
Very Difficult & 14 & .5341 & .5873 & .5304 & .4873 & .5348 \\
\hline F Prob. & & .5683 & .0960 & .3937 & .8012 & .4800 \\
H Prob. & .6272 & .0845 & .4956 & .7872 & .3768 \\
\hline
\end{tabular}

* $\mathrm{p}<.05$

$* * \mathrm{p}<.01$

Table VII illustrates an extension of the above approach to the question of adjustment and adaptability. Instead of simply measuring level of adjustment during or after sojourn, Table VII gives results measuring the change in perceived difficulty of adjustment from adjustment during to adjustment after sojourn. The purpose of this test was to eliminate the possibility of subjects' interpreting the $1-5$ scale choices differently; i.e. for accurate results from this test, consistency had to lie only within each subject rather than across subjects for this particular analysis. Results were significant for RTOTAL and all CCAI scales except for RPAC. For RER, RFO, RPAC, and RTOTAL, means were highest for those who found adjustment more difficult upon return than during their sojourn while means were lowest for the group who found the opposite to be true. Means were intermediate for those who reported no change in level of difficulty. Once again, RPA was the exception to this finding. The highest mean for RPA came from the group who reported no change in adjustment. 
TABLE VII

MEANS, F PROBABILITIES, AND H PROBABILITIES FOR CCAI SCALE AND TOTAL RANKS FOR CHANGE IN LEVEL OF DIFFICULTY FROM ADJUSTMENT DURING TO AFTER SOJOURN

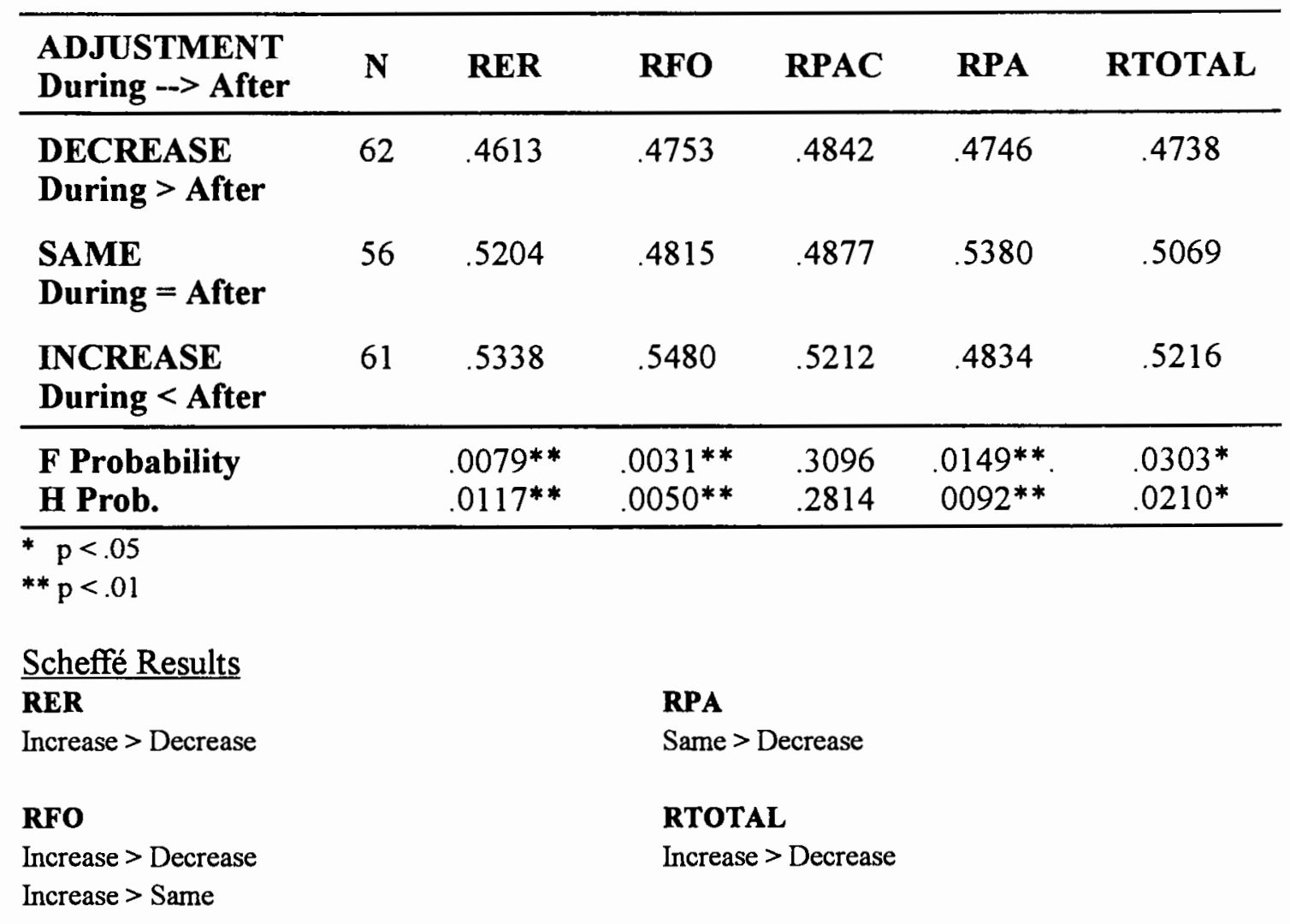

Question 3 - Language Proficiency: Is there a significant relationship between selfperceptions of second language proficiency and self-perceptions of cross-cultural adaptability?

Three demographic questions were created to address this question. The first question was a "yes/no" question asking subjects $(\mathrm{N}=245)$ if they considered themselves to be fluent in a second language (L2). Kelley and Meyers specifically mention that language fluency is not measured by the CCAI since it can easily be measured otherwise (pg. 2). Table VIII below gives credence to the common assumption that L2 proficiency is a vital 
part of successful cross-cultural adaptability: RTOTAL, RER, RFO, and RPAC means were significantly higher $(p<.01)$ in subjects with L2 proficiency than in subjects with no L2 proficiency. RPA means, however, did not show significant difference.

\section{TABLE VIII}

MEANS, F PROBABILITIES AND H PROBABILITIES FOR CCAI SCALE AND TOTAL RANKS FOR SUBJECTS' L2 FLUENCY

\begin{tabular}{lcccccc}
\hline L2 FLUENCY & N & RER & RFO & RPAC & RPA & RTOTAL \\
\hline No L2 Fluency & 167 & .4741 & .4755 & .4851 & .4962 & .4827 \\
L2 Fluency & 78 & .5618 & .5587 & .5388 & .5146 & .5435 \\
\hline F Prob & & $.0000^{* *}$ & $.0000^{*}$ & $.0082^{* *}$ & .3140 & $.0001^{* *}$ \\
H Prob. & & $.0000^{* *}$ & $.0000^{* *}$ & $.0051^{* *}$ & .3166 & $.0001^{* *}$ \\
\hline
\end{tabular}

$* p<.05$

$* * \mathrm{p}<.01$

The second question regarding L2 fluency was identical to the first except that it inquired about fluency of the subjects' parent/s rather than the subjects themselves. This question was based on a similar question asked by Koester (1987) in her survey of students with international ID cards. The question presumes that students whose parents were proficient in an L2 may have had more exposure to an L2 and perhaps to a second culture (through the parents) than subjects whose parents were not proficient in an L2. Results as shown in Table IX below were very close to those for subjects who were fluent themselves in an L2, and thus appear to confirm the above supposition. Again, RPA was the only scale that did not show significance at the .05 level. In fact, the F Probability of the RPA scale appeared to suggest quite the opposite with a high score of .9764 -- indicating almost $0 \%$ probability of significant difference.

Since results for parent/s' and subjects' L2 fluency analyses were statistically 
significant, it seemed that analysis of L2 fluency for subjects and parent/s together might also be interesting. Table $X$ below proved this to be true. For those who believe in the interconnectedness of language and culture, CCAI means came out exactly as one might predict, ranging from lowest to highest for RTOTAL and all scales, except for RPA, as follows: (1) neither parent/s nor subject fluent, (2) only parent/s fluent, (3) only subject fluent, (4) both parent/s and subject fluent.

TABLE IX

MEANS, F PROBABILITIES, AND H PROBABILITIES OF CCAI SCALE AND TOTAL RANKS FOR PARENT/S' L2 FLUENCY

\begin{tabular}{lcccccc}
\hline L2 FLUENCY & N & RER & RFO & RPAC & RPA & RTOTAL \\
\hline No L2 Fluency & 188 & .4919 & .4900 & .4911 & .5019 & .4937 \\
L2 Fluency & 57 & .5354 & .5415 & .5387 & .5025 & .5295 \\
\hline F Prob & & $.0463^{*}$ & $.0080^{* *}$ & $.0322^{*}$ & .9764 & $.0269^{*}$ \\
H Prob. & & .0523 & $.0100^{* *}$ & $.0230^{*}$ & .9320 & $.0363^{*}$ \\
\hline
\end{tabular}

$* p<.05$

$* * p<.01$

TABLE X

MEANS, F PROBABILITIES AND H PROBABILITIES FOR CCAI SCALE AND TOTAL RANKS FOR L2 FLUENCY FOR PARENT/S \& SUBJECTS

\begin{tabular}{lcccccc}
\hline L2 FLUENCY & N & RER & RFO & RPAC & RPA & RTOTAL \\
\hline No Fluency & 142 & .4703 & .4712 & .4782 & .4936 & .4783 \\
Parent/s Fluent & 25 & .4957 & .4995 & .5242 & .5112 & .5077 \\
Subject Fluent & 46 & .5587 & .5479 & .5309 & .5277 & .5413 \\
Parent/s \& & 32 & .5664 & .5743 & .5500 & .4957 & .5466 \\
Subject Fluent & & & & & & \\
\hline F Prob & & $.0001^{* *}$ & $.0001^{* *}$ & $.0205^{*}$ & .4631 & $.0002^{* *}$ \\
H Prob. & & $.0001^{* *}$ & $.0001^{* *}$ & $.0122^{*}$ & .5605 & $.0005^{* *}$ \\
\hline
\end{tabular}

\begin{tabular}{llll}
\hline$* \mathrm{p}<.05$ & Scheffé Results & & \\
${ }^{* *} \mathrm{p}<.01$ & ER & RFO & RTOTAL \\
& Parents/Subj. $>$ No Fluency & Parents/Subj. $>$ Parents & Parents/Subj. > No Fluency \\
& Subj. Fluent $>$ No Fluency & Subj. Fluent $>$ No Fluency & Subj. Fluent $>$ No Fluency
\end{tabular}


A third question asked subjects to rate themselves on a scale of one (none) to 6 (fluent), representing their level of fluency specifically in the L2 of the host culture where they had sojoumed. This question applied only to those who had had previous experience abroad, and so involved only a subset $(\mathrm{N}=179)$ of the 245 participants of the first two questions. Subjects who reported English as the primary host culture language were also excluded. Results from Table XI below show a significant difference in the means of the six L2 skill level groups for all scales and total scores, except for the RPA scale. The consistency of nonsignificance in RPA means for all three language proficiency questions should be noted as well as the consistent significance of RER, RFO, RPAC and RTOTAL in all three questions. It is also interesting to note that the means for RTOTAL correspond neatly in ascending order from the lowest level to the highest level of perceived L2 proficiency.

\section{TABLE XI}

MEANS, F PROBABILITIES, AND H PROBABILITIES FOR CCAI SCALE AND TOTAL RANKS FOR SKILL IN HOST CULTURE L2 (Where primary language is not English)

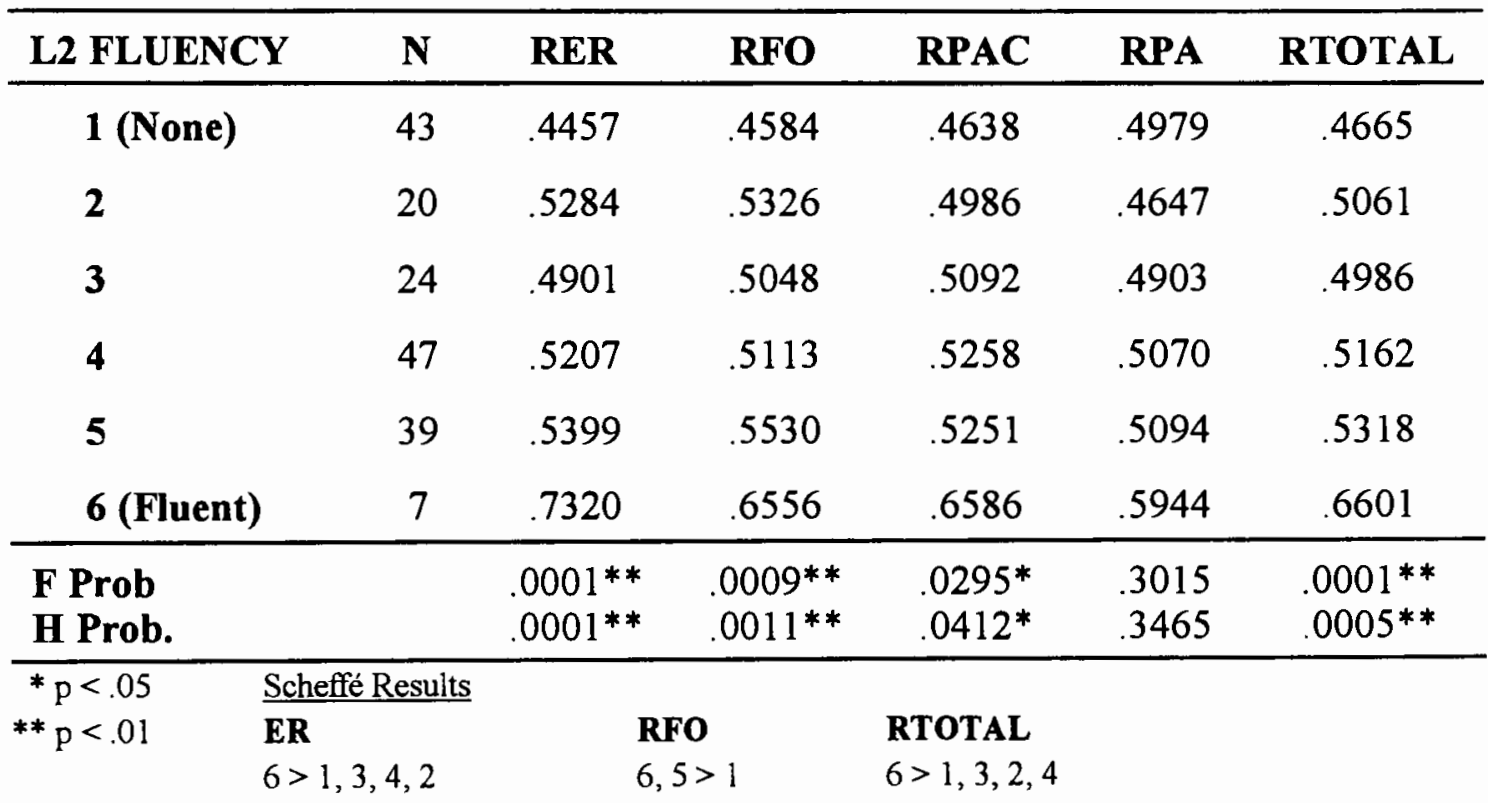


A fourth question asked sojourners to estimate what percent of verbal interaction during their sojourn took place in the host culture L2. Table XII below shows a correlation between increased use of the host culture L2 and self- perceptions of cross-cultural adaptability. This is not surprising since percentage of use of an L2 in the respective host culture is probably a reflection of perceived fluency.

TABLE XII

CORRELATIONS OF PERCENTAGE OF HOST CULTURE L2 USE WITH CCAI SCALE AND TOTAL RANKS

$$
N=178
$$

\begin{tabular}{llllll}
\hline & RER & RFO & RPAC & RPA & RTOTAL \\
\hline PERCENT L2 & $.2832^{* *}$ & $.2334^{* *}$ & .1157 & .0363 & $.2219^{* *}$ \\
USE & $.2642^{* *}$ & $.2195^{* *}$ & .0953 & .0194 & $.2001^{* *}$ \\
\hline
\end{tabular}

$* \mathrm{p}<.05$

Pearson correlation coefficient $=$ top number

$* * \mathrm{p}<.01$

Spearman correlation coefficient $=$ bottom number

Question 4 - Length of Previous Experience Abroad: Is there a significant relationship between length of previous experience abroad and self-perceptions of cross-cultural adaptability?

Since the demographic questionnaire asked subjects to report time abroad as an open-ended question rather than as a categorical question, statistical analysis could make use of both correlational and difference of means testing. The following results were based on subjects' total time abroad. This included not only the length of subjects' reported sojourn with one of the two institutions of this study but also combined the lengths of up to three previous sojourns; i.e., any time abroad, regardless of purpose, was included in the calculations of subjects' total previous experience abroad. As indicated in Table XIII, there was a significant correlation between length of all previous experience abroad (TOTAL 
TIME) and RFO, RPAC, and RTOTAL. For RER, the Spearman correlation coefficient was significant while the Pearson correlation coefficient was not. Once again, RPA showed no significance for either the Pearson or Spearman correlation coefficient and was, in fact, slightly negative for both coefficient values.

TABLE XIII

CCAI PEARSON AND SPEARMAN PRODUCT-MOMENT CORRELATIONS (r's) WITH TOTAL TIME ABROAD

$$
N=245
$$

\begin{tabular}{llllll}
\hline & RER & RFO & RPAC & RPA & RTOTAL \\
\hline TOTAL & .1058 & $.1454^{*}$ & $.1443^{*}$ & -.0173 & $.1271^{*}$ \\
TIME & $.2080^{* *}$ & $.2497^{* *}$ & $.2521^{* *}$ & -.0496 & $.2218^{* *}$ \\
\hline
\end{tabular}

$* \mathrm{p}<.05$

Pearson correlation coefficient $=$ top number

${ }^{* *} \mathrm{p}<.01 \quad$ Spearman correlation coefficient $=$ bottom number

Since many studies attempt to identify a specific time frame for maximizing effective cross-cultural learning, this study categorized sojourners into groups representing length of total previous experience abroad. Subjects with no previous experience abroad were divided into two categories: those who had had no cross-cultural classes and those who had had one or more cross-cultural classes. Means of the resulting 7 groups were significantly different for RFO, RPAC and RTOTAL. Scheffé's test, however, did not show significant differences in any specific pairs of group mean scores. It is interesting to note that although RPA was not the only scale with nonsignificant mean differences, it was the only scale in which the extreme high and low means were reversed from what one would predict. In other words, subjects with no previous experience abroad had the highest mean while subjects with over 3 years experience abroad had the lowest mean for this scale. RTOTAL scores, on the other hand, followed "intuitional" results with the "no experience" group 
having the lowest mean and the group with the most experience having the highest mean. It is also interesting to note that subjects with only cross-cultural class(es) experience ranked higher than subjects with 1 to 4 months experience on all four scales and RTOTAL.

\section{TABLE XIV}

MEANS, F PROBABILITIES AND H PROBABILITIES FOR CCAI SCALE AND TOTAL RANKS FOR CROSS-CULTURAL EXPERIENCE

\begin{tabular}{|c|c|c|c|c|c|c|}
\hline EXPERIENCE & $\mathbf{N}$ & RER & RFO & RPAC & RPA & RTOTAL \\
\hline $\begin{array}{l}\text { No Experience } \\
\text { (Sojourn/Class) }\end{array}$ & 23 & .4497 & .4311 & .4409 & .5333 & .4638 \\
\hline Class(es) Only & 12 & .5148 & .5210 & .5238 & .5433 & .5257 \\
\hline$\leq 1$ month & 40 & .4742 & .4674 & .4689 & .4861 & .4741 \\
\hline$>1 \mathrm{mo}$. to $4 \mathrm{mo}$. & 82 & .4980 & .4928 & .4857 & .5075 & .4960 \\
\hline$>4$ mo. -1 yr. & 50 & .5133 & .5407 & .5421 & .4751 & .5178 \\
\hline$>1$ yr. - 3 yrs. & 17 & .5713 & .5212 & .5356 & .5275 & .5389 \\
\hline$>3$ yrs. & 21 & .5378 & .5626 & .5628 & .4970 & .5401 \\
\hline $\begin{array}{l}\text { F Prob } \\
\text { H Prob. }\end{array}$ & & $\begin{array}{l}.0954 \\
.1734\end{array}$ & $\begin{array}{l}.0053^{* *} \\
.0102^{* *}\end{array}$ & $\begin{array}{l}.0133^{* *} \\
.0101^{* *}\end{array}$ & $\begin{array}{l}.4144 \\
.3300\end{array}$ & $\begin{array}{l}.0451^{*} \\
.0756\end{array}$ \\
\hline
\end{tabular}

${ }^{*} \mathrm{p}<.05$

$* * \mathrm{p}<.01$

\section{ANALYSES FOR TESOL MINORS}

Since this study stemmed from concern specifically for the cross-cultural adaptability of individuals entering the profession of Teaching English to Speakers of Other Languages (TESOL), the following section focuses specifically on the group of participants with academic minors in this area of study. (Note: The two participating institutions did not offer TESOL as a major.) Table XIV indicates significant differences in RFO, RPAC, and RTOTAL means for groups of minors as listed, with the Scheffé test specifically indicating higher means for TESOL vs Business minors and for Social Sciences vs Business in RFO. 
TABLE XV

MEANS, F PROBABILITIES AND H PROBABILITIES FOR CCAI SCALE AND TOTAL RANKS FOR MINOR AREA OF STUDY

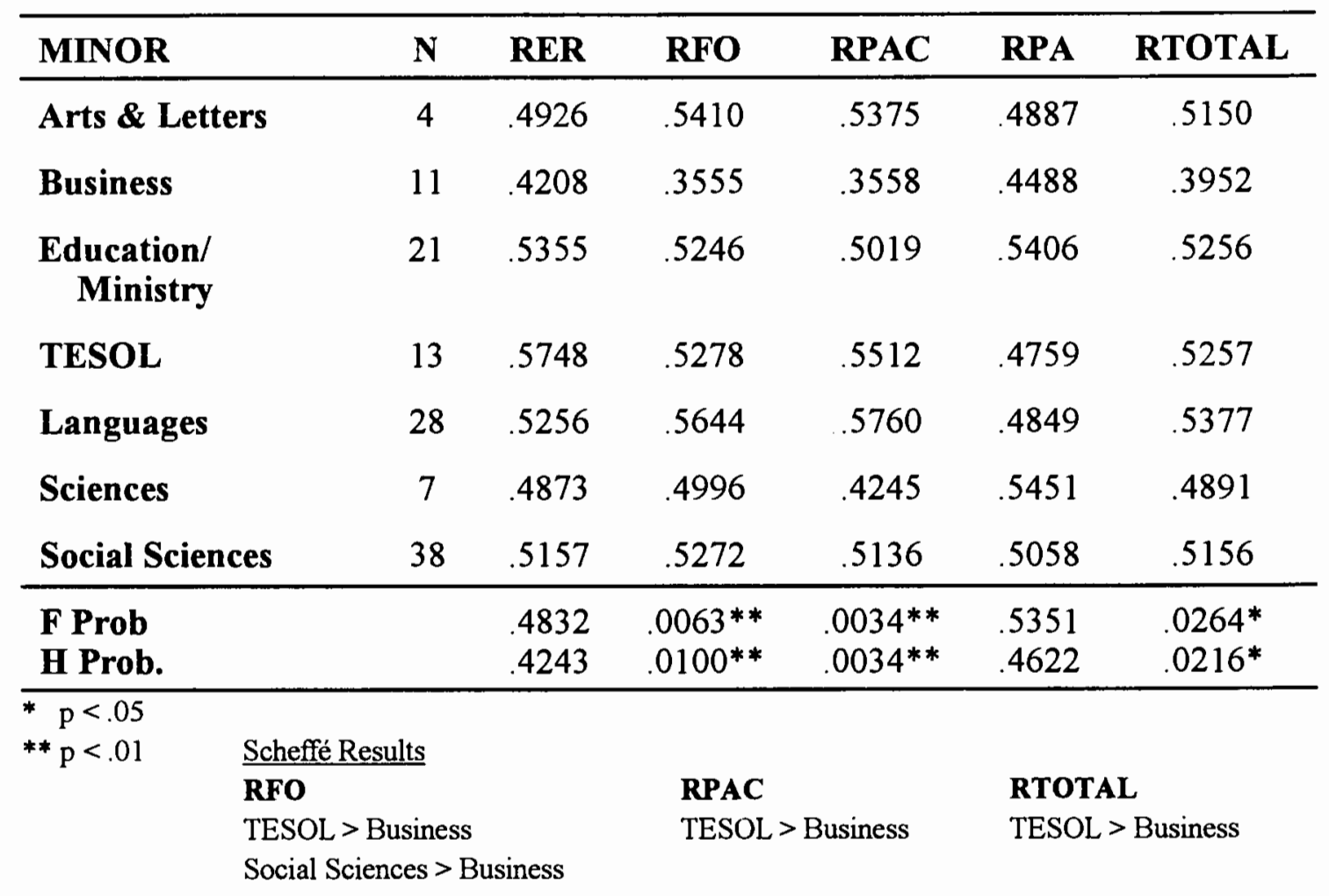

When TESOL minors $(\mathrm{N}=28)$ were compared with all Non-TESOL minors $(\mathrm{N}=217), \mathrm{CCAI}$ means proved to be significantly higher for TESOL minors for RFO and RPAC as shown in Table XVI. In an attempt to understand this difference, comparisons were run with the same two groups for the variables of time, L2 use, percent interaction and adjustment while on a study abroad as well as total experience/time abroad. As Tables XVII and XVIII indicate, length of time on study abroad and length of total previous experience abroad were significantly higher for the TESOL minors than for Non-TESOL minor. It appears that TESOL minors chose longer study abroad experiences and, as a group, had an average of just over one year experience abroad as opposed to just under $1 / 2$ year experience for the group of Non-TESOL minors. 
TABLE XVI

MEANS, F PROBABILITIES AND H PROBABILITIES FOR CCAI SCALE AND TOTAL RANKS FOR TESOL VS NON-TESOL MINORS

\begin{tabular}{lcccccc}
\hline MINOR & N & RER & RFO & RPAC & RPA & RTOTAL \\
\hline TESOL & 28 & .5256 & .5644 & .5760 & .4849 & .5377 \\
Non-TESOL & 217 & .4990 & .4939 & .4927 & .5043 & .4975 \\
\hline F Prob & & .3458 & $.0096^{* *}$ & $.0041^{* *}$ & .4609 & .0558 \\
H Prob. & & .2893 & $.0063^{* *}$ & $.0100^{* *}$ & .4876 & .0530 \\
\hline
\end{tabular}

TABLE XVII

MEANS, F PROBABILITIES AND H PROBABILITIES FOR TIME, PERCENT INTERACTION, AND L2 USE ON STUDY ABROAD FOR TESOL VS NONTESOL MINORS

\begin{tabular}{lcccc}
\hline MINOR & N & $\begin{array}{c}\text { TIME } \\
\text { (In yrs.) }\end{array}$ & $\begin{array}{c}\text { PERCENT } \\
\text { INTERACTION }\end{array}$ & $\begin{array}{c}\text { PERCENT } \\
\text { L2 USE }\end{array}$ \\
\hline TESOL & 17 & .2635 & 64.8824 & 45.8824 \\
Non-TESOL & 161 & .1914 & 63.5404 & 48.0124 \\
\hline F Prob & & $.0030^{* *}$ & .8271 & .8112 \\
H Prob. & & $.0018^{* *}$ & .7429 & .8273 \\
\hline
\end{tabular}

$* * \mathrm{p}<.01$

TABLE XVIII

MEANS, F PROBABILITIES AND H PROBABILITIES FOR ADJUSTMENT DURING AND AFTER SOJOURN ABROAD AND TOTAL TIME OF EXPERIENCE ABROAD FOR TESOL AND NON-TESOL MINORS

\begin{tabular}{llccc}
\hline MINOR & N & ADJUST. DURING & ADJUST. AFTER & TOTAL TIME \\
\hline TESOL & 17 & 2.5882 & 2.9412 & 1.1635 \\
Non-TESOL & 161 & 2.5590 & 2.5404 & .4228 \\
\hline F Prob & & .8956 & .1773 & $.0000^{* *}$ \\
H Prob. & .9043 & .1914 & $.0000^{* *}$ \\
\hline
\end{tabular}

** $\mathrm{p}<.01$ 


\section{AGE, GENDER, SATISFACTION}

Although the primary questions of this study have already been addressed above, this section is included as a point of interest for the two participating institutions and for other researchers who may be working with the CCAI. Also, all three variables addressed in the following--age, gender, and satisfaction with sojourn abroad are addressed by Kelley and Meyers in their results and so can be compared with their study.

Age

Kelley and Meyers grouped their subjects $(\mathrm{N}=653)$ by the following ages: under 20 , $20-29,30-39,40-49,50$ or over. Since the present study involved subjects who had attended or graduated from college/university only within the last three years, Kelley and Meyers' groupings were not appropriate. The majority of students in the present study were typical college ages of $20-25$, although there were several who were $40-50$ years old. Before grouping subjects, correlational tests were run. Results from these tests in Table XIX showed no significant relationship between age and any of the CCAI scales or RTOTAL. After determining age groups of 18-19, 20-25, and >25, CCAI means were significantly different for RER, RFO and RTOTAL as indicated in Table XX. It should be noted that unlike the present study's results, Kelley and Meyers' research showed a significant difference in RPA means for age. Especially interesting are the results of their subanalyses which indicate significantly higher means for the under 20 age group in comparison to every other group. 
TABLE XIX

PEARSON AND SPEARMAN PRODUCT-MOMENT CORRELATIONS WITH

CCAI SCALE AND TOTAL RANKS AND AGE

$$
N=245
$$

\begin{tabular}{lccccc}
\hline & RER & RFO & RPAC & RPA & RTOTAL \\
\hline AGE & -.0100 & .0155 & -.0208 & -.0044 & -.0002 \\
& -.0665 & -.0733 & -.0837 & .0232 & -.0733 \\
\hline
\end{tabular}

$\begin{array}{ll}* \mathrm{p}<.05 & \text { Pearson correlation coefficient }=\text { top number } \\ * * \mathrm{p}<.01 & \text { Spearman correlation coefficient }=\text { bottom number }\end{array}$

TABLE XX

MEANS, F PROBABILITIES AND H PROBABILITIES FOR CCAI SCALE AND TOTAL RANKS FOR AGE

\begin{tabular}{lcccccc}
\hline AGE GROUPS & N & RER & RFO & RPAC & RPA & RTOTAL \\
\hline $\mathbf{1 8 - 1 9}$ yrs. & 23 & .4288 & .4380 & .4282 & .5142 & .4523 \\
$\mathbf{2 0 - 2 5}$ yrs. & 192 & .5068 & .5075 & .5076 & .4989 & .5052 \\
$>\mathbf{2 5}$ yrs. & 30 & .5272 & .5153 & .5246 & .5130 & .5200 \\
\hline F Prob & & $.0239^{*}$ & .0573 & $.0308^{*}$ & .7704 & $.0440^{*}$ \\
H Prob. & & $.0314^{*}$ & .1018 & $.0304^{*}$ & .8055 & $.0401^{*}$ \\
\hline
\end{tabular}

* $p<.05$

$\underline{\text { Scheffé Results }}$

\section{RER}

$>25 \mathrm{yrs}>18-19 \mathrm{yrs}$.

20-25 yrs $>18-19$ yrs.

\section{RPAC}

20-25 yrs > 18-19 yrs.

\section{Gender}

In Kelley and Meyers' study, approximately $2 / 3$ of the 653 subjects were males and approximately $1 / 3$ were female. Their results showed females as having significantly higher means than males for RFO, RPAC, and RPA. The present study, with approximately $2 / 3$ females and 1/3 males had similar results with significantly higher means for females in RFO and RPAC as evidenced in Table XXI below. 
TABLE XXI

MEANS, F PROBABILITIES AND H PROBABILITIES FOR CCAI SCALE AND TOTAL RANKS FOR GENDER

\begin{tabular}{lcccccc}
\hline GENDER & N & RER & RFO & RPAC & RPA & RTOTAL \\
\hline Female & 161 & .4937 & .5147 & .5160 & .4987 & .5058 \\
Male & 84 & .5180 & .4775 & .4757 & .5085 & .4949 \\
\hline F Prob & & .1993 & $.0419^{*}$ & $.0388^{*}$ & .5787 & .4425 \\
H Prob. & & .1969 & $.0302^{*}$ & $.0319^{*}$ & .6376 & .5396 \\
\hline
\end{tabular}

${ }^{*} \mathrm{p}<.05$

$\underline{\text { Satisfaction }}$

Subjects in this study were asked to indicate satisfaction with their study abroad experience by marking "Yes" (Satisfied), "No" (Not satisfied) or "Mixed." The following results compared these three groups of subjects first according to their CCAI ranks, then with the variables of time (length of study abroad), percent of interaction with host culture members and percent of L2 (host culture) use while abroad. As evidenced in Table XXII, those who were satisfied with their study abroad experience had significantly higher means than those who were not satisfied for RER, RFO and RTOTAL. Table XXIII indicates that those who (1) chose longer study abroad experiences, (2) interacted more with host culture members and (3) used the primary host culture language more were also more satisfied with their cross-cultural experience. 
TABLE XXII

MEANS, F PROBABILITIES AND H PROBABILITIES FOR CCAI SCALE AND TOTAL RANKS FOR SATISFACTION

\begin{tabular}{|c|c|c|c|c|c|c|}
\hline SATISFACTION & $\mathbf{N}$ & RER & RFO & RPAC & RPA & RTOTAL \\
\hline YES & 146 & .5301 & .5224 & .5187 & .4996 & .5177 \\
\hline NO & 7 & .3623 & .3484 & .4116 & .5056 & 4070 \\
\hline MIXED & 47 & .4658 & .4877 & .4819 & .4853 & .4802 \\
\hline $\begin{array}{l}\text { F Prob } \\
\text { H Prob. }\end{array}$ & & $\begin{array}{l}.0004^{* *} \\
.0021^{* *}\end{array}$ & $\begin{array}{l}.0015^{* *} \\
.0022^{* *}\end{array}$ & $\begin{array}{l}.0751 \\
.0811\end{array}$ & $\begin{array}{l}.7900 \\
.6647\end{array}$ & $\begin{array}{l}.0037^{* *} \\
.0046^{* *}\end{array}$ \\
\hline $\begin{array}{l}\text { Scheffé } \\
\text { RER } \\
\text { Yes }>1\end{array}$ & , Mixed & & $\begin{array}{l}\text { RFO } \\
\text { Yes > } \\
\text { Mixed }\end{array}$ & & $\begin{array}{l}\text { RTO } \\
\text { Yes > }\end{array}$ & \\
\hline
\end{tabular}

TABLE XXIII

MEANS, F PROBABILITIES AND H PROBABILITIES FOR TIME, PERCENT OF INTERACTION WITH HOST CULTURE AND PERCENT OF L2 (HOST CULTURE) USE BY SATISFACTION

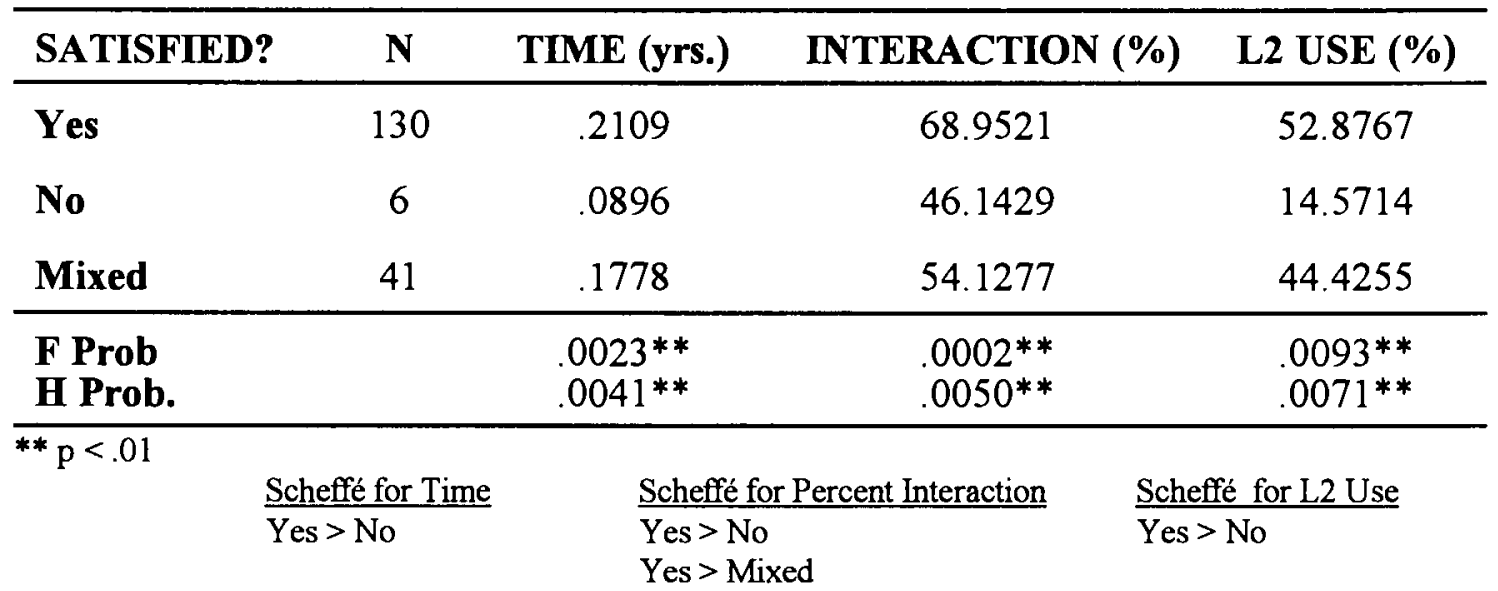




\section{CHAPTER V}

\section{SUMMARY AND CONCLUSIONS}

\section{INTRODUCTION}

For the TESOL profession, whose very definition depends on interaction with individuals from other cultures, it seems that cross-cultural adaptability should, without question, be of primary concern both for trainers of ESL teachers and for the teachers themselves. The field of cross-cultural/intercultural communication is relatively new, however, and not much empirical evidence is available to support current understanding of what does or does not constitute cross-cultural adaptability. This problem has been compounded by a lack of readily-available measurement instruments due to the multidimensional nature of cross-cultural communication. In an attempt to address this problem, Kelley and Meyers (1993) recently created the 50-item, Likert scale Cross-Cultural Adaptability Inventory (CCAI). The CCAI defines the construct of cross-cultural adaptability through a total score and four contributing dimensions: Emotional Resilience (ER), Flexibility/Openness (FO), Perceptual Acuity (PAC), and Personal Autonomy (PA).

Using Kelley and Meyers' CCAI, the purpose of this study was twofold: (1) to increase understanding of cross-cultural adaptability by studying the effect of four independent variables--host culture contact, cultural distance, second language proficiency, and length of previous experience abroad--on the dependent variable of cross-cultural adaptability; (2) to explore the possibility of using the CCAI for self-awareness and crosscultural training in the TESOL profession. 
Two hundred and forty-five college/university students from two private institutions (Eastern Mennonite University in Virginia and Goshen College in Indiana) participated in the study through completion of the CCAI and a 20-item demographic survey. Subjects were selected based on their previous cross-cultural experience through study abroad programs and/or personal experience abroad as well as location and length of experience. Twenty-eight subjects with academic minors in TESOL were also specifically selected. This chapter provides a summary and discussion of data from these subjects (presented in Chapter IV), presents conclusions based upon the results, examines limitations and the value of this study, provides implications for the TESOL profession and recommends areas for further research. For convenience, the four research questions are recapped below:

1. Is there a significant relationship between host culture contact during previous experience abroad and self-perceptions of cross-cultural adaptability?

2. Is there a significant relationship between cultural distance of previous study abroad experience and self-perceptions of cross-cultural adaptability?

3. Is there a significant relationship between self-perceptions of second language proficiency and cross-cultural adaptability?

4. Is there a significant relationship between length of previous study abroad experience and self-perceptions of cross-cultural adaptability?

\section{Additional Question}

5. A fifth question that arose during the course of this study was: Is there a significant relationship between TESOL and Non-TESOL minors and self-perceptions of crosscultural adaptability?

\section{OVERALL FINDINGS}

Before addressing results from each of the primary research questions, overall findings are first presented below since interpretation of these findings may, in turn, affect interpretation of the individual questions. Two readily-noticeable observations can be made from looking at a summary of results in Table XXIII below: 
TABLE XXIV

SUMMARY OF DIFFERENCE OF MEANS AND CORRELATION RESULTS FOR ALL VARIABLES FOR CCAI SCALES AND TOTAL RANKS

\begin{tabular}{|c|c|c|c|c|c|}
\hline \multicolumn{6}{|c|}{ DIFFERENCE OF MEANS ANALYSES } \\
\hline VARIABLES & RER & RFO & RPAC & RPA & RTOTAL \\
\hline Living Arrangements & * & * & $*$ & & $*$ \\
\hline \multicolumn{6}{|l|}{ Location } \\
\hline \multicolumn{6}{|l|}{ Cultural Distance } \\
\hline Adjustment During... & $* *$ & & & * & ** \\
\hline \multicolumn{6}{|l|}{ Adjustment After... } \\
\hline Change in Adjustment & ** & ** & & $* *$ & * \\
\hline L2 Fluency - Subject & ** & ** & ** & & ** \\
\hline L2 Fluency - Parent/s & * & ** & * & & * \\
\hline $\begin{array}{l}\text { L2 Fluency - } \\
\text { Parent/s \& Subject }\end{array}$ & $* *$ & ** & * & & ** \\
\hline Skill in L2(Host Culture) & ** & ** & $*$ & & ** \\
\hline Total Time Abroad & & $* *$ & $* *$ & & \\
\hline Minor & & ** & $* *$ & & * \\
\hline TESOL vs Non-TESOL & & $* *$ & $* *$ & & \\
\hline Age & * & & * & & * \\
\hline Gender & & $*$ & * & & \\
\hline Satisfaction & ** & ** & & & $* *$ \\
\hline \multicolumn{6}{|c|}{ CORRELATIONAL ANALYSES } \\
\hline Contact with Host Culture (\%) & $* *$ & ** & ** & & $* *$ \\
\hline L2 use (\%) & $* *$ & $* *$ & & & $* *$ \\
\hline Cultural Distance & & & $*$ & & \\
\hline Total Time Abroad & & $*$ & $*$ & & * \\
\hline \multicolumn{6}{|l|}{ Age } \\
\hline $\begin{array}{ll}{ }^{*} \mathrm{p}<.05 & \mathrm{RER}=\text { Emotional Resilie } \\
*^{*} \mathrm{p}<.01 & \mathrm{RFO}=\text { Flexibility/Openn }\end{array}$ & & Persc & $\begin{array}{l}1 \text { Acuity } \\
\text { utonomy }\end{array}$ & & $\mathrm{AL}=\mathrm{To}$ \\
\hline
\end{tabular}


The first observation is that, overall, the variables addressed in this study seemed to be significantly related to self-perceptions of cross-cultural adaptability. Only four tests-correlation of age with CCAI means, difference of means for adjustment during study abroad, location, and perceived cultural distance--did not indicate significance in any of the four CCAI scales or RTOTAL.

The second observation pertains to the distribution of significant results among the four scales and RTOTAL, particularly in relation to RPA. To begin with, although all scale and RTOTAL ranks correlated significantly with each other, RPA had the lowest correlation coefficients with all other scales and RTOTAL. Of 21 analyses (testing for either correlation or significant difference of means), RER was significant in 9, RFO was significant in 11, RPAC was significant in 12, RTOTAL was significant in 13, and RPA was significant only in two. The relevant question seems to be, why was RPA so consistently nonsignificant in the analyses? One possibility could simply be due to chance results. Another possibility could either be that personal autonomy is not as integral to cross-cultural adaptability as the three other dimensions or that it is not significantly related to the specific variables addressed by this study. After looking more closely at RPA in relation to specific results from both the present study and Kelley and Meyers' study, however, a third possibility seems to be that, for some reason, RPA may not consistently be measuring what it was designed to measure. To review the intended characteristics of RPA briefly,

The PA scale items assess the extent to which a person has evolved a personal system of values and beliefs which he or she feels comfortable and confident enough to act on amidst diversity. At the same time, the scale examines the extent to which this person respects others and their value systems. Finally, it examines how much a person feels pressured to change in such a cross-cultural environment; the scale thus looks at a person's ability to remain non-defensive and open to such change. (Pg. A-11)

The present study postulates that while RPA may correctly identify individuals at the 
high end of the scale (1-6) as being those with self-perceptions of high strength of personal values and beliefs, it may do so at the cost of confounding results by including those who may also tend to be inflexible and/or overconfident. Upon re-examination of the 7 questions comprising the RPA scale listed below, only the second question regarding equality of race seems relevant to capturing traits of flexibility. The other 6 questions seem to hold the possibility of being interpreted negatively as oppositional statements as well as positively as "strength of character/self-concept" statements:

1. I believe that I can accomplish what I set out to do, even in unfamiliar settings.

2. All people, of whatever race, are equally valuable.

3. If my ideas conflicted with those of others who are different from me, I would follow my ideas rather than theirs.

4. I feel free to maintain my personal values, even among those who do not share them.

5. I prefer to decide from my own values, even when those around me have different values.

6. My personal value system is based on my own beliefs, not on conformity to other people's standards.

7. I expect that others will respect me, regardless of their cultural background.

The following observations elaborate on this further:

\section{Observations for significant RPA'S:}

RPA was significant in two analyses--"Adjustment During Sojourn" and "Change in Adjustment During Sojourn." In the former, the group of subjects with the highest mean RPA were the group who rated adjustment during their study abroad experience as "Not At All Difficult." Although not significantly different, the highest means for all other scales resulted from the group on the opposite end of the spectrum, who found adjustment during sojourn "Very Difficult." In the second analysis, the subjects with the highest mean RPA 
were those who indicated no change in degree of difficulty from during to after return. In contrast, significantly high means for RER, RFO, and RTOTAL resulted from the group who found returning more difficult than being in the host culture. In these results it seems that RPA was "at odds" with its companion scales. Several possible reasons could explain this: (1) Perhaps the subjects in this study with high RPA's reported themselves as not having a difficult time adjusting during study abroad experiences because they had already reached a "higher level" of cross-cultural adaptability (in which case the reported RPA would be an accurate reflection of their adaptability). (2) Possibly, highly autonomous individuals simply do not experience adjustment difficulties. (3) Subjects with high RPA's may not have reached the realm beyond ethnocentricity and thus may not have had to "deal with" change and concurrent adjustment difficulties. (4) Possibly a mixture or none of the above account for the results.

\section{RPA vs RFO}

Because Kelley and Meyers give no indication that RPA should respond differently than the other CCAI scales, the following explores the possibility mentioned above that RPA may indeed unintentionally measure lack of flexibility in addition to its original intention of measuring confidence in personal values and beliefs. The most relevant channel to address this alternative explanation (with the current data available) seems to be an examination of a possible negative correlation between RFO and RPA ranks; i.e. following this hypothesis, individuals who ranked themselves high in Flexibility/Openness would have tended to rank themselves low on Personal Autonomy and vice versa. This was found to be true in the following cases: 
Total Experience Abroad. Subjects with no cross-cultural experience abroad (or through classes) rated themselves lowest in RFO and highest in RPA while subjects with the most experience abroad rated themselves exactly opposite (lowest in RPA and highest in RFO).

Gender. Females had a higher mean than males for RFO but a lower mean for RPA.

Minors. The following three minors had their highest means for RFO and lowest means for RPA: Arts \& Letters, Languages, Social Sciences. Business minors had the opposite means with the highest for RPA and the lowest for RFO.

TESOL vs Non-TESOL Minors. The RFO mean for TESOL minors, as expected, was significantly higher than that of Non-TESOL minors. It should also be noted that, although not significantly so, the RPA mean for TESOL minors was unexpectedly lower than that for Non-TESOL minors.

Satisfaction. Subjects who were satisfied with their sojourn abroad experience had their highest mean on the RFO scale and their lowest mean on the RPA scale. The group of subjects who were not satisfied with their sojourn abroad experience had their highest mean on the RPA scale and their lowest mean on the RFO scale.

Kelley and Meyers' Results. Kelley and Meyers' results were interesting in this respect also. Looking at the variable of age, subjects in their study under 20 years old had significantly lower means for FO, as one would expect, than every other age group except for the 20-29 group. For PA, however, this same group (under 20) had higher means than those of all other age groups. If FO and PA both measure desirable cross-cultural qualities, these results bear further examination. Why should the youngest group of subjects have scored higher than anyone else for a CCAI dimension and lower than anyone else on another dimension for the same variable? It does not seem logical to conclude that the under-20 age 
group should serve as a model for personal autonomy. Rather, a greater likelihood seems that these results could be indicative of stereotypically youthful assertion carrying with it a degree of inflexibility.

Kelley and Meyers' results for PA for educational level also went against intuition: the mean PA for "High School Graduates" was significantly higher than the mean PA for "Graduate Work" subjects, and "Some College" subjects had a significantly higher mean than either "College Graduates (4 year)" or "Graduate Work" subjects. Again, it doesn't seem to make sense to say that, as a result of these analyses, researchers should look at the possibility that less education results in more "autonomous" and, therefore, cross-culturally adaptable individuals. Rather, it seems that age, or something else, could be a confounding variable in the research. A last example of "opposing" results can be found for the "Missionary" occupation group. Not including the occupation group of "Other," PA means for the "Missionary" occupation group were higher than those of any of the seven other occupation groups listed (Business/Industry, Education, Government/Military, Human Services, Student, and Training/Consultation). For FO, however, the "Missionary" group had lower means than did Education, Human Services and Training/Consultation groups.

While the above results are by no means conclusive, they seem to at least call for a re-examination of the construct validity of the PA scale. This should be kept in mind while looking at the results of the four research questions below. (Note: The above rationale concerning RPA will not be repeated below.)

\section{RESEARCH QUESTIONS}

Question 1 - Host Culture Contact: Is there a significant relationship between host culture contact during previous experience abroad and self-perceptions of cross-cultural 
adaptability?

For four out of five tests, the answer to this question was "yes." Those who had had a higher percentage of interaction with the host culture and those who had spent more time living with host culture families perceived themselves to be more culturally adaptable except in the dimension of Personal Autonomy. These results confirmed the view of many researchers who emphasize the importance of meaningful host culture contact for intercultural learning. This would also confirm findings such as Koester's (1987) in which individuals who traveled for leisure purposes (staying in motels/dorms) did not experience as great cross-cultural learning as did their peers who experienced home stays.

Question 2 - Cultural Distance: Is there a relationship between cultural distance of previous study abroad experience and self-perceptions of cross-cultural adaptability?

Although a number of researchers note the potential importance of cultural distance in cross-cultural learning/adaptability, the construct is a difficult one to measure. Babiker, Cox and Miller (1980) appear to have made the most recent attempt to develop a measure of culture distance--the Culture Distance Index (CDI). Their tool, however, involves interviews and extensive knowledge of each host culture, neither of which were feasible for this study. The question ultimately used for measurement was a very brief and simplified adaptation of the CDI, which simply asked subjects to rate the difference between home and host culture on a scale of 1 (very similar) to 6 (very different) for 7 items: food, concept of time, social life, religion, economy, political stability, ethnicity/race and overall culture. Since cultural distance is often intuitively associated with geographic areas, subjects were also asked to provide location of their experience abroad. No significant results were found for location, and only a weak correlation was found for perceived cultural distance with 
CCAI means. Two factors (among others)--length of experience and personality "fit" with a specific culture--may have affected these results

An underlying issue addressed as a fundamental part of the effect of cultural distance was determined to be that of level of adjustment (1) during sojourn, (2) after sojourn, and (3) change in direction between the two; e.g, was there a significant difference between those who an easier time adjusting while abroad then upon return and those who had a more difficult time adjusting while abroad than upon return? RER, RPA (as discussed above) and RTOTAL were significantly different for the levels of adjustment while abroad. The Scheffé test indicated that the "Not At All Difficult" group had the highest CCAI means for RER, RPA and TOTAL. No significant differences were found for adjustment after return from experience abroad. Scheffé results from "Change in Level of Adjustment" indicated that subjects who found adjustment more difficult upon return than during sojourn/s were more adaptable for the RER, RFO and RTOTAL dimensions. These combined results may indicate that more adaptable individuals find it easier to be abroad but also more difficult to adjust upon return. It would make sense, from Bennett's (1995) paradigm of moving from ethnocentrism to ethnorelativism, that these subjects may have experienced internal changes causing them to see their old world in a new light, resulting in increased adaptation difficulties. It would also make sense that those who were more flexible and open were the ones more likely to "allow" and/or welcome these changes.

Question 3- Second Language Proficiency: Is there a relationship between self-perceptions of second language proficiency and cross-cultural adaptability?

This question addressed three separate variables of second language proficiency: (1) general second language proficiency, (2) parent/s' second language proficiency, and (3) 
second language proficiency specific to the host culture of respective study abroad experiences. The first two variables were combined to create a fourth test comparing the results of both subject and parental fluency together. Results for all four analyses indicated significantly higher means for RER, RFO, RPAC and RTOTAL (all except RPA) for subjects who were fluent and/or whose parents were fluent in a second language. These results seem to confirm the importance of second language proficiency as an integral part of effective cross-cultural skills. Subjects who perceived themselves to be fluent clearly had the highest means while subjects who considered themselves to have little or no second language skill clearly had the lowest means.

Question 4 - Length of Previous Experience Abroad: Is there a relationship between length of previous study abroad experience and self-perceptions of cross-cultural adaptability?

Measurement of this question was the most straightforward of the four. Subjects were simply asked to provide length and date/s (approximately) of (1) their study abroad experience and/or (2) other previous experience abroad. Space was allotted on the questionnaire for up to three previous experiences. All experiences listed per subject were added together to give a total length for previous experience abroad. A second question asked subjects to indicate the number of cross-cultural courses that they had taken. Data from this question were used to divide subjects with no experience into two groups: those who had had no cross-cultural classes and those who had had one or more cross-cultural classes. The next five groups were as follows: $<1$ month; $>1$ month -4 months; $>4$ months -1 year; $>1$ year -3 years; $>3$ years. Both correlation and difference of means tests were run. Correlational analysis indicated that RFO, RPAC and RTOTAL had a significantly positive relationship with total length of previous experience abroad. ANOVA 
and Kruskal-Wallace analyses resulted in significant differences for two of these--RFO and RPAC. Scheffé tests did not result in any specific pairs of significantly different means. Results of mean scores were as expected, however, in that those with no previous crosscultural experience (and no classes) had the lowest scores on all CCAI scales (except for RPA) and TOTAL while those with the most experience abroad had the highest means in the same scales. It was interesting to note that subjects with only cross-cultural class/es ranked higher than subjects with 1 to 4 months experience on all four scales and TOTAL. Since these specific means were not necessarily significantly different, however, no conclusions can be made at this point, although further investigation would possibly prove to be of interest.

It should be noted that this research question faced a seemingly insurmountable obstacle: although subjects were originally selected for length and location of study abroad experience, there was no way to control for previous cross-cultural experience outside of the institutional study abroad experience. When looking at total length of experience, it seemed essential to take into consideration not merely the known institutionally-sponsored experiences but also all previous experience. By doing this, however, numerous potentially intervening variables were introduced including factors such as location, age and purpose of experience. Suppose for example, that one subject had traveled to Europe twice for vacation for two weeks, once at age 10 and again at age 16. Suppose another student, a senior in college, went to China to study Chinese with a Chinese family for one month. Although both students would have been gone for a total of one month, it seems likely that their experiences would have had differing results. The one contrast that would not be as likely to be affected by these factors is that between subjects with no experience and any group with at least some experience. Since this analysis was significant (as mentioned 
above), the implication seems to be that at least some experience is better than none. The "fear" discussed in the literature review of the one-month or less sojourn potentially creating false illusions of adaptability was neither supported nor rejected by this study.

Question 5 - Field of study: Is there a significant relationship between area of study and selfperceptions of cross-cultural adaptability?

Since this study arose from concerns connected with the TESOL profession, 28 subjects with TESOL minors were targeted for analysis. (Both participating institutions offered only minors in this field.) Subjects were categorized into the following groups: Arts \& Letters, Business, Education/Ministry, TESOL, Languages, Sciences, and Social Sciences. Since the purpose of the TESOL profession is to work with individuals of other cultures, one would expect these individuals to be among the highest groups of adaptability. Results confirmed this expectation, indicating significant mean differences for RFO, RPA, and RTOTAL. Scheffé test results specifically targeted TESOL minors for being significantly higher than Business minors for these three areas. Scheffé analysis also indicated that Social Science minors had a significantly higher mean than did Business minors for RFO.

As a follow-up, subjects with TESOL minors were compared with those without TESOL minors. Significantly higher means were found for TESOL than for Non-TESOL minors for RFO, RPAC, and RTOTAL In an attempt to provide further insight, six additional tests compared these two groups for the following variables: length, percent of host culture interaction, percent of L2 (host culture) use, adjustment during, and adjustment after study abroad along with total length of previous experience abroad. TESOL minors had significantly higher means than did Non-TESOL minors for length of study abroad and 
length of total previous experience abroad. According to these results, TESOL minors chose longer study abroad experiences and, as a group, had an average of slightly over one year of previous total experience abroad as compared to the Non-TESOL minors who had an average of just under $1 / 2$ year total experience abroad. If the CCAI provides an accurate measure of adaptability, the above results suggest again that increased time abroad is connected to increased adaptability. It would appear that TESOL minors either chose their experience abroad as an outgrowth of their TESOL education, or chose their TESOL minor as a result their experiences/s.

\section{Age, Gender, and Satisfaction with Experience Abroad:}

Analysis of CCAI means for age, gender, and satisfaction with previous experience abroad were run for comparison with results of the same variables for Kelley and Meyers' study ( $\mathrm{N}=653)$. Results from correlational analysis showed no significant relationship between age and any of the CCAI scales or RTOTAL. After determining age groups of 18$19,20-25$, and $>25$, results showed that RER, RFO, and RTOTAL CCAI means were significantly higher for subjects $>25$ years than for 18-19 year old subjects. Scheffé results indicated that the 20-25 year old group RER mean was also significantly higher than the 18-25 group mean. Although Kelley and Meyers used different age groupings, their results concurred with the above results-younger subjects were not shown to be as cross-culturally adaptable as older subjects. These results agree with intuition; it makes sense that 18-19 year old individuals with less education, probably less experience abroad, and simply less "life learning" would be less cross-culturally adaptable than older subjects.

In Kelley and Meyers' study, approximately $2 / 3$ of the 653 subjects were male and $1 / 3$ female. Their results showed females as having significantly higher means than males 
for RFO, RPAC, and RPA. Although the present study had an opposite gender ratio of approximately $2 / 3$ females and $1 / 3$ males, results were similar in that females had significantly higher means than males for RFO and RPAC. Results were reversed for RPA, however, where the mean score for males was higher than that for females.

Results comparing CCAI means with satisfaction of previous experience abroad indicated that subjects who were satisfied with their study abroad experience had significantly higher means than those who were not satisfied for RER, RFO, and RTOTAL. These results corresponded with those of Kelley and Meyers (with the addition of significance for RPAC). Further analyses showed, as expected, that those who (1) chose longer study abroad experiences, (2) interacted more with host culture members and (3) used the primary host culture language more were also more satisfied with their crosscultural experience. It is not possible to discern whether individuals were destined to be more satisfied with their experience abroad because of greater cross-cultural skills to begin with or whether greater satisfaction resulted in higher perceptions of cross-cultural adaptability; i.e., especially for first-time travelers, someone who has had a positive experience abroad is probably more likely to believe he/she can be successful in crosscultural interaction than someone who has had a negative experience.

\section{LIMITATIONS}

A subject so inherently multi-dimensional as cross-cultural studies inevitably brings with it a considerable number of research limitations. The following enlarges upon a number of the limitations specific to this study. 
Objectivity This study is based on the collection of self-report, self-perception data. No behavioral or external measures were used for comparison. There are at least two ways of viewing this self-report data: (1) as scientifically inadequate because of potential skewness caused by subjectivity; (2) as a necessary component for understanding the whole picture of cross-cultural adapatability. This study maintains that both of these viewpoints are accurate.

To elaborate upon the first point, it is true that CCAI results cannot with certainty be equated with behavioral outcomes; i.e., simply because some subjects rated themselves higher or lower on some items does not mean the rating is true behaviorally, or, that the subject is more or less adaptable. To address this, Kelley and Meyers (1993) suggest using their Feedback Form to show correspondence between self-perception and external measures. (The Feedback Form is exactly identical to the original CCAI in form and content except that the questions are asked in the third, instead of first, person. Kelly and Meyers suggest that each subject be rated on the Feedback Form by three different individuals.) Although this merits attention, there are still two foreseeable problems related to objectivity of the data, albeit external data: (1) How does one determine the reliability of these external measures? The selection itself of respondents for feedback may influence the external measures; i.e., individuals giving the feedback may answer differently depending upon their own level of cultural awareness/adaptability; (2) Unless the subjects did not receive feedback results, it seems that feedback responders would have substantial reason to elevate the transparent questions in order to avoid offending the subject.

Looking at self-report data from the second viewpoint, it can be argued that understanding individuals' self-perceptions of cross-cultural adaptability is fundamental to intercultural training and program planning. What if, for instance, (as posited in the 
literature review), short term sojourners had consistently perceived their cross-cultural skills to be greater than those of long-term sojourners? If this was false behaviorally, as intuition would suggest, it seems that program planners and trainers would want to exercise caution when dealing with short-term sojourns and/or sojourners. On the other hand, if selfperception data consistently proved to have a high positive correlation with external measures, it would probably take precedence due to cost and ease of measurement. It should also be noted that some variables, such as perceived cultural distance, may be more appropriately measured by self-perception instruments than external measurements; i.e., for these variables, elicitation of self-perceptions may, in fact, be the intended goal. Ultimately, though it was beyond the scope of this study, it seems that researchers should use both objective and subjective measures for comparison and depth of understanding. Those who do not do so should at least clearly identify which type of data they are relying upon and the concurrent strengths and weaknesses of the methodology employed.

\section{Intervening Variables}

Part of the difficulty of research in the cross-cultural field is the large number of potentially intervening variables. Because of this, the longitudinal study with its descriptive nature may be a better fit for this type of research. Some of the variables not addressed in this study are as follows:

Formal language study. Subjects were asked about their own and their parents' fluency in other languages but were not asked to give a history of formal second language study. This would have provided more data on language exposure, especially for those who had studied a second language but did not consider themselves to be fluent. 
Personality. Even though the CCAI is intended to be a culture-general instrument, Kelley and Meyers (1993) note that some individuals may have a better "fit" with some cultures than others. It seems that these subjects could, likewise, have a better "fit" to one or more of the four CCAI dimensions regardless of external variables.

Extenuating circumstances. Subjects' qualitative comments indicated that circumstances beyond their control sometimes had an effect upon their experience of the sojourn. For example, one student who broke his leg while abroad rated himself very high in "difficulty of adjustment." Another student whose girlfriend broke up with him upon his return rated his return adjustment as very difficult.

Attitude. Attitudes before and after the sojourn were not measured. It is possible that the subjects' attitudes toward their own and the host culture could have influenced their experience.

Pre-and Post-field Training. Can pre- and/or post-field training significantly impact the effects of sojourns abroad? Or, is the experience itself more important than what surrounds it? This study did not address these questions. Although EMU and GC's sojourns abroad varied in the pre- and post-field training, it was beyond the scope of this study to itemize these differences.

Maturational Effects. In order to obtain a large enough sample size representing the variables of interest, it was necessary to elicit data from subjects who had gone abroad within the past three years. Because of this, varying lengths of time had passed between the time subjects had been abroad and the time of responding to the CCAI. This may have affected subjects' answers, especially if experiences abroad continue to affect individuals even after returning as several individuals indicated. In addition, it was not possible to control for timing of other experiences abroad not connected with either institution; i.e., a 
subject who spent two years abroad as a child would probably have been affected differently than the subject who spent two years abroad while a teenager.

\section{Generalizability}

Several factors of subject selection limit generalizability of this study. First, only U.S. subjects participated. Secondly, all subjects had either graduated from or attended one of two Mennonite schools and thus were not likely representative of the mainstream U.S. schooling system. A redeeming value of this, however, could be that the subjects' relative homogeneity may have reduced intervening variables.

\section{Data Analysis}

Since the results of this study were analyzed differently than those listed in the CCAI Manual, they cannot be compared to the standard suggested by Kelley and Meyers as set by their study of 653 individuals considered to be cross-culturally adaptable. The method of analysis used in the present study does not allow analysis resulting in standard absolute scores for comparison. Ranking the data resulted in composite rank scores which were meaningful only in relation to the responses of the $\mathrm{N}=245$ subjects of this study. In order to compare across studies, the raw data from each study would first have to be combined, then ranked together as one study.

\section{THE VALUE OF THIS STUDY}

The present study contributes to the field of cross-cultural/intercultural communication studies in three main ways: through the use and evaluation of the Cross-

Cultural Adaptability Inventory (CCAI), a new measurement instrument developed by Kelley and Meyers (1993); through what is believed to be more appropriate statistical 
analysis for the instrument than originally used; and through the addition of empirical data addressing the variables of host culture contact, cultural distance, second language proficiency, and length of previous cross-cultural experience through sojourn abroad. Each of these three areas is addressed below.

\section{The Cross-Cultural Adaptability Inventory (CCAI)}

Kelley and Meyers (1993) created the Cross-Cultural Adaptability Inventory (CCAI) to address the lack of readily-available instruments to measure cross-cultural adaptability. They list five main purposes for the CCAI as follows (verbatim):

1. To understand the factors or qualities which facilitate cross-cultural effectiveness

2. To become self-aware regarding those factors or qualities in which one is strong and those which need improvement.

3. To improve skills in interacting with people from other cultures, when one is already in a multi-cultural or new-culture setting.

4. To decide whether to work in a culturally diverse company or multinational company, whether to live abroad, and so on.

5. To prepare to enter another culture, such as a multinational environment or a new country, through preparatory training customized to the individual.

After using the CCAI, several questions pertaining to these purposes arose during the course of the present study. The main question concerns the predictive validity of the CCAI. Kelley and Meyers' comments concerning this are somewhat confusing. On the one hand, Purpose \#4 above and the following statements seem to suggest predictive validity:

...Do the scores from the instrument significantly correlate with meaningful external criteria? Could we, for example, select people for cross-cultural assignments or explain why some people are more successful than others in another culture on the basis of the instrument? Because of the methods used in its construction, it is reasonable to expect that the CCAI would have some predictive validity. (pg. 32) 
On the other hand, Kelley and Meyers stress that the CCAI is a self-selection instrument, not a selection instrument and that with this in mind,

The CCAI was not developed to predict success or failure in cross-cultural interaction. In other words, it is not recommended that the CCAI be used to make decisions about another person's future, such as whom to send abroad or whom to put in charge of a multi cultural team. Instead, after learning about cross-cultural adaptability and examining their own assets and liabilities in this area, people taking the instrument can make decisions about their own readiness to interact with people from other cultures. (pg 12)

If the CCAI is not meant to be predictive, on what basis should people using the CCAI "make decisions about their own readiness to interact with people from other cultures?"

A second, related question concerns the use of the CCAI as a standard for effective cross-cultural adaptability. On the one hand, Kelley and Meyers state,

"Those utilizing the CCAI should understand that it is more important for each person to look at how his or her own scores relate to one another (i.e., which are higher and which lower), than to compare these scores with the maximum possible scores or with the scores of others completing the CCAI. (pg. 13)

On the other hand, the scoring/results diagram is designed in such a way that CCAI participant scores are shown in relation to the fiftieth percentile scores of the original group used to test the CCAI $(\mathrm{N}=653)$. It seems that this would encourage the comparison of oneself to others that Kelley and Meyers specifically discourage.

The third question concerns the use of the CCAI as a research instrument. It should be noted, as Kelley and Meyers acknowledge, that the CCAI was designed as a training tool, not as a research instrument. However, in the following statement by Kelley and Meyers, research is the first of a list of three uses for the CCAI: "The CCAI should be used as a basis for understanding research findings, self-assessment of one's capacities, and planning for self-improvement" (pg. 13). Because of a scarcity of research instruments measuring cross-cultural adaptability, future researchers may continue to use this instrument. It seems 
that clearer guidance is needed for its use in this way. Kelley and Meyers devote a significant section of their CCAI manual to results of statistical analysis but do not offer an interpretation of the results beyond an item-by-item analysis. In light of the concerns regarding the dimension of Personal Autonomy expressed above, it seems that researchers should carefully examine their results before offering conclusions based on the use of the CCAI. On the other hand, however, with the exception of RPA, overall results in the present study using the CCAI statistically confirmed conclusions found in the literature review regarding cross-cultural adaptability.

\section{Method of Statistical Analysis for the Cross-Cultural Adaptability Inventory}

Kelley and Meyers list three researchers who have completed dissertations using the CCAI. All three researchers along with Kelley and Meyers used parametric analysis on their raw data. The present study determined that parametric analysis on the raw CCAI data was inappropriate due to the ordinality of the Likert-scale data. It is hoped that the present study will serve to bring attention to the questions of appropriateness of statistical methodology used for Likert-scale data in future research.

\section{Empirical Results}

Many researchers point toward a scarcity of empirical research addressing crosscultural theory. As a quantitative study, the present study served to add to this limited empirical base. Findings confirmed the importance of type and amount of host culture contact, second language proficiency, and length of experience abroad for successful crosscultural adaptation. 


\section{IMPLICATIONS FOR ESL}

The following implications for ESL are based on the assumption that the CCAI holds merit for measuring the construct of cross-cultural adaptability:

First, regarding second language proficiency, results from this study clearly supported the interconnectedness of language and culture learning. For TESOL programs who do not already require second language proficiency for those joining the profession, it seems only logical to do so or at least to consider doing so.

A second implication of this study is that both ESL teachers and administrators of ESL programs should encourage, and consider requiring, study abroad as a way of increasing cross-cultural adaptability. Although language departments have historically been the primary ones to require experience abroad, it seems that the TESOL profession should be no less concerned with the potential for cross-cultural learning through experience abroad. At the very least, deliberate discussion regarding the issue should take place among those responsible for curricula within TESOL programs. Results from the present study showed that subjects with no previous cross-cultural experience rated themselves lower than any other group on overall cross-cultural adaptability and in the specific dimensions of Flexibility/Openness and Perceptual Acuity. For individuals who do decide to participate in experience abroad programs, this study found that living with host culture families resulted in greater cross-cultural adaptability than living in dorms/motels or similar arrangements where interaction with host culture members was not found to be as great.

A third recommendation concerns the use of the Cross-Cultural Adaptability Inventory (CCAI). Although questions arose for the scale measuring Personal Autonomy, results for all other scales were as expected. Because of this, it seems reasonable that the 
CCAI could be profitably used by trainers of ESL teachers to stimulate discussion and cultural self-awareness, especially in light of the fact that the CCAI was originally created specifically for cross-cultural training (rather than for research). Before participants respond to the CCAI, however, the ordinal nature of the scales should be made clear; i.e. participants may respond differently to the same questions simply because of different interpretations of the 1-6 scale measurements. Results of RPA and RFO should also be discussed when interpreting results. Without further research, the CCAI is not recommended as a tool for predicting success or failure abroad.

\section{SUGGESTIONS FOR FUTURE RESEARCH}

Suggestions for further research in the area of cross-cultural adaptability are as follows:

1. Future researchers who use the CCAI should pay particular attention to the dynamics of the Personal Autonomy scale. It would be particularly interesting to focus on the possible interactional effects of the Flexibility/Openness scale with the Personal Autonomy scale.

2. More research is needed to address the implications of using Likert scale data such as that employed by the CCAI. Comparative studies using different statistical techniques are needed for determination of the most appropriate analyses.

3. Future research using the CCAI should consider exploring other behavioral/situational measures in conjunction with the CCAI as external measures of cross-cultural adaptability.

4. Future research is needed to compare the effectiveness of course work vs field experience for cross-cultural learning/adaptability. 
5. Future research in cross-cultural studies should address the possible relationship of cultural distance and cross-cultural adaptability. Although some researchers suggest there is a relationship between the two, the present study neither supported nor rejected this hypothesis.

6. Future researchers studying the results of sojourn abroad should address the effects of pre- and post-field training.

7. Since cross-cultural interaction always involves more than one culture, more research is needed to simultaneously compare the effects of sojourn abroad upon interacting members of both the host and visiting culture.

\section{SUMMARY}

Using the Cross-Cultural Adaptability Inventory (Kelley and Meyers, 1993), this study found overall significant results between self-perceptions of cross-cultural adaptability and the four independent variables addressed--host culture contact, cultural distance, second language proficiency, and length of previous experience abroad. Of the four variables, cultural distance had the weakest correlations with adaptability. Both in the present study and Kelley and Meyers' study, results for the Personal Autonomy scale did not show the same consistency of significance as did its three companion dimensions of Emotional Resilience, Flexibility/Openness and Perceptual Acuity. Results discussed in this chapter showed that, in several tests, Personal Autonomy seemed to be "in opposition" to those of Flexibility/Openness. Possibilities for this were offered and discussed.

Limitations discussed in this chapter included objectivity, intervening variables, generalizability, and methodology of data analysis. The value of the study included (1) evaluation of the CCAI in general and for TESOL specifically, (2) the innovative statistical 
methodology used, and (3) the addition of empirical data related to the construct of crosscultural adaptability. Because of the results of this study, implications for ESL focused on encouraging study abroad and second language proficiency as a means of growth in crosscultural adaptability. The CCAI was recommended for increased self-awareness but not as a predictive tool for cross-cultural success or failure. The chapter concluded with suggestions for future research. 


\section{REFERENCES}

Amir, Yehuda \& Ben-Ari, Rachel. (1983). Cognitive cultural learning, intergroup contact and change in ethnic attitudes and relations. (ERIC Document, ED 262 135.)

Allen, K. W. (1993). Cultural diversity and collaboration: Educating teachers for the future. (ERIC Document, ED 365 640.)

Armstrong, G. (1984). Life after study abroad: A survey of undergraduate academic and career choices. The Modern Language Journal, 68 (1), 1-6.

Babiker, I. E., Cox, J. L., \& Miller, P. M. (1980). The measurement of cultural distance and its relationship to medical consultations, symptomatology and examination performance of overseas students at Edinburgh University. Social Psychiatry, 15, 109-116.

Bennett, M. (1995). Beyond tolerance: Intercultural communication in a multicultural society. (Cassette No. 105-1021-95). TESOL Conference, Long Beach, CA.

Blalock, H. M. (1972). Social statistics. New York, NY: McGraw Hill, Inc.

Bogardus, E.S. (1925). Measuring social distance. Journal of Applied Sociology. 9, 299308.

Brislin, R.W., Landis, D., \& Brandt, M.E. (1983). Conceptualizations of intercultural behavior and training. In D. Landis \& R.W. Brislin (Eds.), Handbook of Intercultural Training I. New York: Pergamom Press.

Carlson, J. S. \& Widaman, K. F. (1988). The effects of study abroad during college on attitudes toward other cultures. International Journal of Intercultural Relations, 12 , $1-17$.

Cicekdag, M. A. (1987). Cultural distance and the foreign language teaching/learning process. (ERIC Document, ED 338 073.)

Condon, E. C. (1984). Cross-cultural interferences affecting teacher-pupil communication in American schools. International and Intercultural Communication Annual, 108117. 
Cooper, A., Beare, P., \& Thorman, J. (1990). Preparing teachers for diversity: A comparison of student teaching experiences in Minnesota and South Texas. Action in Teacher Education, 12(3), 1-4.

Council on International Educational Exchange. (1990). A national mandate for education abroad: Getting on with the task. (ERIC Document, ED 331 340.)

Damen, L. (1987). Culture learning: The fifth dimension in the language classroom. Reading, Massachusetts: Addison-Wesley Publishing Company.

Day, J. T. (1987). Student motivation, academic validity, and the summer language program abroad: An editorial. The Modern Language Journal, 1ㅡ, 261-266.

Dinges, N. (1983). Intercultural competence. In D. Landis \& R. W. Brislin (Eds.), Handbook of Intercultural Training I. New York: Pergamom Press.

Engle, J. (1987). Study abroad: It's good for students, if it's well planned. Chronicle of Higher education, 260-268.

Field, L. F. (1987). The effect of multicultural counseling training on multicultural sensitivity of graduate students. Doctoral dissertation. Indiana State University, IN.

Furnham, A. (1988). The adjustment of sojourners. In Y. Y. Kim \& W.B. Gudykunst (Eds.), Cross-cultural adaptation: Current approaches. Intercultural Communication Annual, 11, 42-62. Newberry, CA: Sage.

Furnham, A. \& Bochner, S. (1986). Culture shock: Psychological reactions to unfamiliar environments. New York: Methuen.

George, Mary. (1991). Cultural diversity in public elementary schools: an examination of principals' cultural adaptability and student achievements. Dissertation. University of $\mathrm{La}$ Verne, CA.

Gingerich, O. J. (1995). Internationalizing General Education: A Case Study of EMC and the Global Village Curriculum. Doctoral dissertation. Eastern Mennonite University, VA.

$\checkmark$ Goldstein, D. L. (1992). A comparison of the effects of experiential training on sojourners' cross-cultural adaptability. Dissertation Abstract. Florida International University, FL.

Goodwin, C. D. \& Nacht, M. (1988). Abroad and beyond (Institute of International Education Research Report). Cambridge: Cambridge University Press. 
Griffin, K. (1989). New goals for teaching language: An experience in undergraduate programs in Spain. Hispania, $\underline{72}, 774-779$.

Grisbacher, J. C. (1991). Effects of social interaction with host and conationals on the psychological adjustment of sojourning students: A review of the literature. (ERIC Document, ED 335 598.)

Grove, C. L. (1983). What research and informed opinion have to say about very short exchange programs (VPS). (ERIC Document, ED 243 772.)

Gudykunst, W. B. \& Hammer, M. R. (1983). Basic training design: Approaches to intercultural training. In D. Landis \& R. W. Brislin (Eds.), Handbook of Intercultural Training I. New York: Pergamom Press.

Gullahorn, J. \& Gullahorn, J. (1963). An extension of the U-curve hypothesis. Journal of Social Issues, 19(3), 33-47.

Grubb, H. J. \& Ollendick, T. H. (1986). Culture-distance perspective: An exploratory analysis of its effect on learning and intelligence. International Journal of Intercultural Relations, 10 , 399-414.

YHannigan, T. (1990). Traits, attitudes, and skills that are related to intercultural effectiveness and their implications for cross-cultural training: A review of the literature. International Journal of Intercultural Relations, 2 , 382-393.

Hansel, B. (1986). The AFS impact study: Final report. (ERIC Document, ED 285 795.)

Hansel, B. \& Grove, N. (1986). International student exchange programs: Are the educational benefits real? NASSP Bulletin, 84-90.

Hoopes, D. S. (1979). Intercultural communication concepts and the psychology of intercultural experience. In M. D. Pusch (Ed.), Multicultural education: A crosscultural training approach (pp. 10-38). Yarmouth, Maine: Intercultural Press.

Hoopes, D. S., \& Pusch, M. D. (1979). Definition of terms. In M. D. Pusch (Ed.), Multicultural education: A cross-cultural training approach (pp. 2-8). Yarmouth, Maine: Intercultural Press.

Juffer, K. A. (1993). The first step in cross-cultural orientation: Defining the problem. In R. M. Paige (Ed.), Education for the Intercultural Experience. Yarmouth, Maine: Intercultural Press.

Kauffman, N., Martin, J., \& Weaver, H. (1992). Students abroad: Strangers at home Yarmouth, Maine: Intercultural Press. 
Kealey, D. J. (1989). A study of cross-cultural effectiveness: Theoretical issues, practical applications. International Journal of Intercultural Relations, 13, 387-428.

Kealey, D. J., \& Rueben, B. (1983). Cross-cultural personnel selection critieria, issues and methods. In D. Landis \& R. W. Brislin (Eds.), Handbook of Intercultural Training I. New York: Pergamom Press.

Kelly, C. \& Meyers, J. E. (1993). The cross-cultural adaptability inventory manual. Minneapolis, MN: National Computer Systems, Inc.

Kim Y. Y. (1979). Intercultural communication education: Some philosophical issues. In W. G. Davey (Ed.), Intercultural theory and practice: perspectives on education, training and research (pp. 246-260). La Grange Park, IL: Intercultural Network, Inc.

Kim, Y. Y. (1988). Communication and cross cultural adaptation. Philadelphia: Multilingual Matters.

Klemp, G.O. (1979). Identifying, measuring, and integrating competence. In P. Pottinger \& J. Goldsmith (Eds.), New directions in experiential learning: Defining and measuring competence. San Francisco: Jossey-Bass

Klineburg, O. \& Hull, W. F. (1979). At a foreign university: An international study of adaptation and coping. New York: Praeger.

Koester, J. (1986). A profile of foreign language majors who work, study, and travel abroad. The Modern Language Journal, $\underline{70}$, 21-27.

Koester, J. (1987). A profile of the U.S. student abroad: 1984-85. (ERIC Document, ED 297 589.)

Larke, P. J. (1990). Cultural diversity awareness inventory: Assessing the sensitivity of preservice teachers. Action in Teacher Education, 12(3), 23-29.

Larke, P. J., Wiseman, D. \& Bradley, C. (1990). The minority mentorship project: Changing attitudes of preservice teachers for diverse classrooms. Action in Teacher Education, 12(3), 5-11.

Lysgaard, S. (1955). Adjustment in a foreign society: Norwegian Fulbright grantees visiting the United States. International Social Science Bulletin, 7, 45-51.

Mahan, J. M. \& Stachowski, L. (1990). New horizons: Student teaching abroad to enrich understanding of diversity. Action in Teacher Education, 12(13), 13-21. 
Marshall, G. (1988). Issues in international education. North Central Association Quarterly, 63(2), 372-368.

Martin, J. (1987). The relationship between student sojourner perceptions of intercultural competencies and previous sojourn experience. International Journal of Intercultural Relations, 11, 39-48.

Menanteau-Horta, D. (1983). The impact of participation and social contacts on international attitudes of youth: The case of Bolivia and Chile. (ERIC Document, ED 232 942.)

Norusis, M. J. (1992). SPSS/PC+ Manual (Version 5.0). Chicago, IL: Library of Congress.

Oberg, K. (1960). Culture shock: Adjustment to new cultural environments. Practical Anthropology, 7, 177-182.

Pai, Y. (1984). Cultural diversity and multicultural education. International and Intercultural Communication Annual, 7-9, 27.

Paige, R M. (1993). On the nature of intercultural experiences and intercultural education. In R. M. Paige (Ed.). Education for the Intercultural Experience. Yarmouth, Maine: Intercultural Press.

Pearce, (1983). As cited in Hansel, B. (1986). The AFS impact study: Final report. (ERIC Document, ED 285 795.)

Pruit, F. (1978). The adaptation of African students to American society. International Journal of Intercultural Relations, 2, 90-116.

Rohrlich, B. F. \& Martin, J. (1991). Host country and reentry adjustment of student sojourners. International Journal of Intercultural Relations, 15, 153-162.

Samover, L. A. (1979). Intercultural communication education: Some philosophical issues. In W. G. Davey (Ed.), Intercultural Theory and Practice: Perspectives on Education, Training and Research (pp. 246-260). La Grange Park, IL: Intercultural Network, Inc.

Schwarzwald, J. (1985). Carry-over of contact effects from acquainted to unacquainted targets. Journal of Multilingual and Multicultural Development, $\underline{6}(3), 297-311$.

Sikkema, M. \& Niyekawa, A. (1987). Design for Cross Cultural Learning. Yarmouth, Maine: Intercultural Press, Inc. 
Sikkema, M. \& Niyekawa, A. (1977). Cross-cultural learning \& self-growth: Getting to know ourselves and others. New York, NY: International Association of Schools of Social Work.

Stewart, E. (1979). Research in intercultural communication. In W. G. Davey (Ed.), Intercultural theory and practice: Perspectives on education, training and research (pp. 8-20). La Grange Park, IL: Intercultural Network, Inc.

Szalay, L. B. \& Maday, B. C. (1983). Implicit culture and psychocultural distance. American Anthropologist, 85, 110-118.

Taylor, E. W. (1994). Intercultural competency: A transformative learning process. Adult Education Quarterly, 44(3), 154-174.

Triandis, H. C. (1993). Comments on "Multicultural Career Counseling." Career Development Quarterly, 42(1), 50-52.

Wan, T., Chapman, D. W., Biggs, D.A. (1992). Academic stress of international students attending U.S. universities. Research in Higher Education, 33(5), 607-623.

Weaver, G. (1993). In R. M. Paige (Ed.). Education for the Intercultural Experience Yarmouth, Maine: Intercultural Press.

Wilson, A. (1983). A case study of two teachers with cross-cultural experience: They know more. Educational Research Quarterly, $\underline{8}(1), 78-85$.

Wilson, A. (1993). Conversation partners: Helping students gain a global perspective through cross-cultural experiences. Theory into Practice, $\underline{32}$ (1), 21-26.

Wiseman, R. L \& Koester, J. (1993). Intercultural Communication Competency. Newbury Park, CA: SAGE Publications. 
APPENDIX A

FORM LETTERS:

EASTERN MENNONITE UNIVERSITY AND GOSHEN COLLEGE 
September 22, 1995

I am a 1989 graduate of Eastern Mennonite College (University) and am currently working on a Master's Degree (TESOL) from Portland State University in Oregon. For my thesis, I am studying the relationship between study abroad experiences and cross-cultural adaptability. Because of EMU and Goshen's unique history of cross-cultural requirements, I have chosen to gather data from students who have attended or who are currently attending either institution.

Orv Gingerich and the Alumni Office at EMU, who are working with me on this study, have identified you as a student/alumnus who could provide valuable data for this research. The results could have implications for study abroad programs in general and will be of interest to EMU and Goshen's cross-cultural programs in particular.

The enclosed "CCAI" questionnaire (50 questions) and Demographic Data (20 questions) are together designed to take 20 to 30 minutes to complete. There is a stamped, selfaddressed return envelope enclosed for your convenience. Please return both parts of the data to me by OCTOBER 12th.

You are under no obligation to participate in this study; however, if you do participate (1) all information will remain anonymous and confidential and (2) I will be able to complete my master's thesis. A copy of the final results will be made available at both EMU and Goshen by April, 1996.

Thanks for your consideration and/or participation! If you have any questions or concerns, please feel free to call me at home (219) 862-1910 or work (219) 264-4488

Sincerely,

\section{Heidi King}

P.S. The gum is a small thank you for your "Extra" time and effort. (-) 
September 22, 1995

I am a 1989 graduate of Eastern Mennonite College (University) and am currently working on a Master's Degree (TESOL) from Portland State University in Oregon. For my thesis, I am studying the relationship between study abroad experiences and cross-cultural adaptability. Because of Goshen and EMU's unique history of cross-cultural requirements, I have chosen to gather data from students who have attended or who are currently attending either institution.

Wilbur Birky and Stan Miller, who are working with me on this study, have identified you as a student/alumnus who could provide valuable data for this research. The results could have implications for study abroad programs in general and will be of interest to Goshen and EMU's cross-cultural programs in particular.

The enclosed "CCAI" questionnaire (50 questions) and Demographic Data (20 questions) are together designed to take 20 to 30 minutes to complete. There is a stamped, selfaddressed return envelope enclosed for your convenience. Please return both parts of the data to me by OCTOBER 12th.

You are under no obligation to participate in this study; however, if you do participate (1) all information will remain anonymous and confidential and (2) I will be able to complete my master's thesis. A copy of the final results will be made available at both Goshen and EMU by April, 1996.

Thanks for your consideration and/or participation! If you have any questions or concerns, please feel free to call me at home (219) 862-1910 or work (219) 264-4488.

Sincerely,

Heidi King

P.S. The gum is a small thank you for your "Extra" time and effort. $\odot$ 
APPENDIX B

DEMOGRAPHIC SURVEYS:

EASTERN MENNONITE UNIVERSITY AND GOSHEN COLLEGE 


\section{DEMOGRAPIIIC INFORMATION}

If you have gone on an EMU Cross.Cullural Seminar (CCS), please answer the following questions according to your CCS

II you have not gone on a Cross.Cultural Seminar, please answer the following questions with respect to any other experience living abroad or in another cullure that you have had (See $\$ 9$ )

If you have never lived in another cullure. your inpul is still needed to all questions that pertain to you. Added comments at any point are welcome! THANK YOU!

Please fill in the demographic information below. This information is crucial to the study.

1. Birthdale:

2. Gender: $\begin{array}{lll}1 & 1 & \text { Female } \\ 1 & 1 & \text { Male }\end{array}$

3. Whal is/was your major?

Minor?

4. Do you consider yourself lluent (or fully conversant) in any language(s) besides English?

I I no

I I yes

Which language (s)?

5. Do you consider your parent (s) fluent (or fully conversant) in any language besides English?

I I no

I 1 yes

Which language (s)?

6. Have you gone on a Cross-Cullural Seminar (CCS) with EMU?

1 I no

I l yes

For how long?

years

monlhs

weeks

7. When were you there? (Be specilic, il possible) From

to

8. Where did you go for your CCS?

9. Have you had any other experience/s living abroad or with cultures other than your own?

(Be specific, if possible.) $\quad$ । l yes I I no

City, Country
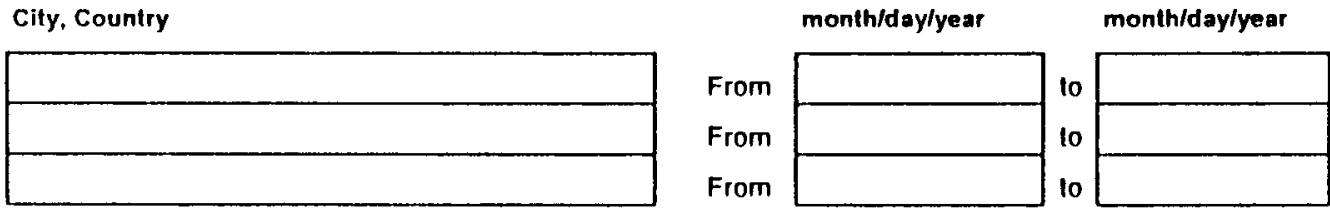

10. Rate your overall adjusiment during your CCS experience.

I I very difficull

I ] dilficult

Cimmicnis:

I somewhat difficull

( ) not very difficult

I I nol at all dilficull

11. Rale your overall adjustmenl immedialely after relurning from your CCS

I ] very difficull

[ ] difficull

Comments:

I somewhal difficult

l I nol very difficult

[ ] nol al all difficult 
12. Were you satisfied with your CCS experience?

I 1 Yes
I I No
I I Mixed

Commicins:

13. What were your living arrangements while on your CCS? (More than one oplion below may apply.)

I I dormitory or molel/holel with American group

I I host culture family wilh another study abroad student (s)

I I host culture family by yourself

1 ] other

14. What percentage of your tolal CCS time was spent interacting with members of the host cullure?

$\%$ (approximalely)

16. Whal was the primary language of the host cullure during your CCS and your skill level in lhat language?

Hosl Culture Language

Your Skill Level in Host Cullure Language (Circle appropriate number)

\begin{tabular}{|l|llllllll|}
\hline & (None) & 1 & 2 & 3 & 4 & 5 & 6 & (Fluent) \\
\hline
\end{tabular}

16. What percentage of your spoken communicalion during your CCS was in the host culture language?

$\%$ (approximately)

17. On the following ilems, compare/contrast your experience in the host culture with your experience in your own cullure by circling a number from:

$1<-$ very similar to very different $\rightarrow>6$.
a) Food
b) Concepl of Time
c) Social Life
d) Religion
e) Economy
1) Political SIabillity
g) Ethnicily/Race
h) OVERALL Cullure

$\begin{array}{lllllll}\text { a) } & 1 & 2 & 3 & 4 & 5 & 6 \\ \text { b) } & 1 & 2 & 3 & 4 & 5 & 6 \\ \text { c) } & 1 & 2 & 3 & 4 & 5 & 6 \\ \text { d) } & 1 & 2 & 3 & 4 & 5 & 6 \\ \text { e) } & 1 & 2 & 3 & 4 & 5 & 6 \\ \text { n } & 1 & 2 & 3 & 4 & 5 & 6 \\ \text { g) } & 1 & 2 & 3 & 4 & 5 & 6 \\ \text { h) } & 1 & 2 & 3 & 4 & 5 & 6\end{array}$

18. How many on-campus cross-cullural courses have you completed for credil?

(List any course--sociology, hislory, anthropology. lit. etc.--whose main content locused on aspects of other cultures.)

Course Name

Approx. course length

\begin{tabular}{|l|l|}
\hline & \\
\hline & \\
\hline & \\
\hline & \\
\hline & \\
\hline
\end{tabular}

19. How much conlact do you currenlly maintain with individuals whom you mel while on a CCS?

I ] None

1 ] 1 - 2 limes per year

1 12 - 5 limes per year

1 1 5 - 10 times per year

I I monthly contact

I I weekly contacl

Commiens:

I I daily conlacl

20. ADOITIONAL COMMENTS:

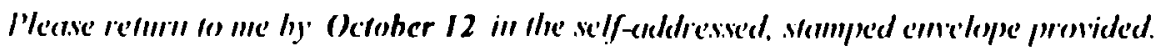
Therwk.s for your time and effort! 


\section{DEMOGRAPIIIC INFORMATION}

If you have gone on a Goshen Sludy-Service Term (SST). please answer the following questions according to your SST.

If you have not gone on a Study-Service Term, please answer the following questions with respect to any other experience living abroad or in another culture that you have had (See \#9)

$\square$ If you have never lived in anolher culture, ynur input is still needed to all questions that pertain to you. Added comments at any point are welcome! THANK YOU!

Please fill in the demographic information below. This information is crucial to the study.

1. Birthdate:

2. Gender: I I Female

3. What is/was your major?

Minor?

4. Do you consider yourself fluent (or fully conversant) in any language(s) besides English?

l I no

I ] yes

Which language (s)?

5. Do you consider your parent (s) fluent (or fully conversanl) in any language besides English?

l I no

[ ] yes

Which language (s)?

6. Have you gone on a Study-Service Term (SST) wilh Goshen?

I I no

I I yes

For how long?

years

monihs

weeks

7. When were you there? (Be specilic, if possible)

From

10

8. Where did you go for your SST?

9. Have you had any olher experience/s living abroad or with cullures other than your own? (Be specific, il possible.) I I yes $\mid$ I no city, Country

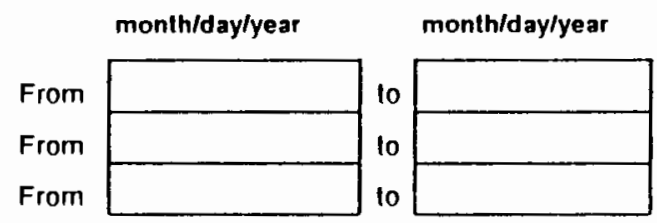

10. Rale your overall adjusiment during your SST experience.

l ] very difficull

(1) difficult

Cimmentis:

[ ] somewhat difficult

I I not very diflicult

i i not al all difficult

11. Rale your overall adjustmenl immediately afler relurning from your SST.

I I very difficull

I I difficull

I I somewhal dirficull

I I not very difficull

[ ] not at all difficull

Commenrs: 
12. Were you satisfied wilh your SST experience?

[ ] Yes
[ ] No
[ ] Mixed

Comments:

13. What were your living arrangements while on your SST? (More than one option below may apply)

I I dormitory or molel/holel with American group

I ] host culture family with another sludy abroad sludent (s)

I I host cullure family by yourself

I other

14. What percentage of your total SST time was spent interacting with members of the host culture?

$\%$ (approximalely)

15. What was the primary language of the host cullure during your SST and your skill level in that language?

Host Culture Language

Your Skill Level In Host Culture Language (Circle appropriate number)

\begin{tabular}{|l|lllllllll}
\hline & (None) & 1 & 2 & 3 & 4 & 5 & 6 & (Fluent) \\
\hline
\end{tabular}

16. What percentage of your spoken communicalion during your SST was in the host culture language?

$\%$ (approximately)

17. On the following ilems, compare/contrast your experience in the host culture with your experience in your own culture by circling a number from:

$1<--$ very similar to very different $\rightarrow 6$.
a) Food
b) Concept of Time
c) Social Lile
d) Religion
e) Economy
n) Political Stabillity
g) Ethnicity/Race
h) OVERALL Culture

\begin{tabular}{|c|c|c|c|c|c|}
\hline a) & 1 & 2 & 3 & 4 & 5 \\
\hline b) & 1 & 2 & 3 & 4 & 5 \\
\hline c) & 1 & 2 & 3 & 4 & 5 \\
\hline d) & 1 & 2 & 3 & 4 & 5 \\
\hline e) & 1 & 2 & 3 & 4 & 5 \\
\hline n) & 1 & 2 & 3 & 4 & 5 \\
\hline ()) & 1 & 2 & 3 & 4 & 5 \\
\hline h) & 1 & 2 & 3 & 4 & 5 \\
\hline
\end{tabular}

18. How many on-campus cross-cullural courses have you completed for credil?

(List any course--sociology, hislory, anthropology, lit, etc --whose main conlent locused on aspects of olher cultures.)

Course Name

Approx. course length

\begin{tabular}{|l|l|}
\hline & \\
\hline & \\
\hline & \\
\hline & \\
\hline & \\
\hline
\end{tabular}

19. How much contact do you currently maintain with individuals whom you mel while on a SST?

[ I None

[ ] 1 - 2 times per year

[ ] 2 - 5 times per year

l 15 - 10 limes per year

[ ] monihly contact

[ ] weekly contacl

Comments:

I J daily contact

20. ADDITIONAL COMMENTS:

Please remun to me by Octoher 12 ill the self-addressed, stamped emelope provided. Thanks.for your rime and efforr! 
APPENDIX C

CATEGORIES FOR MAJORS/MINORS 
CATEGORIES FOR MAJORS/MINORS

$\underline{\text { Arts \& Letters }}$

Art

Music

Theatre

Business

Accounting

Business

Organizational Management

Education/Ministry

English

Special Ed

Health \& PE

Elementary Ed

Coaching

Camping,Rec \& Youth Ministries

Youth Ministries

Bible

Missions

Language

Spanish

French

German

TESOL $\underline{\text { Sciences }}$

Biology

Chemistry

Dietetics

Natural Science

Nursing

Physics

Forestry

Environmental Studies

International Agriculture

Math

Engineering

Social Sciences

Family Studies

Social Work

Sociology

Psychology

Communication

History

Economics

Peace Studies

Liberal Arts

Liberal Arts

Interdisciplinary 
APPENDIX D

CATEGORIES FOR LOCATIONS 


\section{CATEGORIES FOR LOCATIONS}

$\underline{\text { Africa }}$

Africa

Botswana

Burkino Faso

Ivory Coast

Kenya

Tanzania

Zambia

Zaire

Asia

Bangladesh

China

Indonesia

Japan

Hong Kong

Papua New Guinea

Thailand

Taiwan

Nepal

Majuro Marshall Islands

Middle East

Middle East

Israel

Europe/Great Britain

Europe

Germany

France

Italy

Greece

Spain

Sweden

Lithuania

Russia

England

Ireland
Central/South America/West Indies

Costa Rica

Central America

El Salvador

Guatemala

Honduras

Puerto Rico

Mexico

Argentina

Bolivia

Brazil

Paraguay

Venezuela

Haiti

Jamaica

Grenada

Guadeloupe

Dominican Republic

North America

Canada

Chicago

Farm Community

Kentucky

Philadelphia

Texas

West Virginia

Washington D.C. 